\title{
A Parameter Sensitivity Analysis of the Effect of Rebar Corrosion on the Stress Field in the Surrounding Concrete
}

\author{
Fangyuan $\mathrm{Li}^{1}$ and Wenya $\mathrm{Ye}^{2}$ \\ ${ }^{1}$ Department of Bridge Engineering, College of Civil Engineering, Tongji University, Shanghai 20009, China \\ ${ }^{2}$ Ningbo Highway Administration Bureau, Ningbo 315040, China \\ Correspondence should be addressed to Fangyuan Li; fyli@tongji.edu.cn
}

Received 16 December 2016; Accepted 4 April 2017; Published 30 April 2017

Academic Editor: Wei Zhou

Copyright ( 2017 Fangyuan Li and Wenya Ye. This is an open access article distributed under the Creative Commons Attribution License, which permits unrestricted use, distribution, and reproduction in any medium, provided the original work is properly cited.

Rebar corrosion results in a change in the stress field in the surrounding concrete, which in turn accelerates the deterioration of the concrete structure. In addition to the protective layer, the compressive stress under which concrete is prestressed also affects the effect of corrosion-induced rebar expansion on the stress field in the concrete. The present study simulates the effect of corrosioninduced rebar expansion on the stress field in the concrete using the finite element method (FEM) by applying a virtual radial displacement to the product of corrosion-induced rebar expansion. Based on an analysis of the effect of multiple rebars on the stress field in ordinary concrete, stress distribution in the protective layer of the concrete is determined. Afterward, the locations where there is damage to the surface concrete caused by rebar corrosion are determined. After verifying the feasibility of the FEM analysis, the effect of corrosion-induced ordinary rebar expansion in a typical prestressed concrete segment is determined by analyzing the characteristics of corrosion-induced rebar expansion occurring in various prestressed concrete specimens.

\section{Introduction}

Because of relatively high adaptability and low cost of concrete materials, concrete has become essential for civil engineering projects. Reinforced concrete structures are extensively used in civil engineering projects and have become a major type of structure. However, rebar corrosion caused by adverse working conditions (marine and industrial environments), environmental pollution (increased $\mathrm{CO}_{2}$ concentration and acid rain), and improper treatments (spraying deicing salt onto road and bridge surfaces) has already become a widespread phenomenon that occurs in concrete structures. Rebar corrosion can, at best, affect the usability and durability of a structure and, at worst, can reduce the carrying capacity of the structure or even lead to failure of the structure. At the 2nd International Conference on the Durability of Concrete, Professor Mehta from the University of California, Berkeley, USA, noted that the major causes of concrete deterioration today were, in order of decreasing importance, rebar corrosion, frost action in cold climates, and physicochemical effects in aggressive environments [1-5].
People have been trying to solve the unique degradation problems that affect the service life of concrete since reinforced concrete was first developed in the 19th century and prestressed tendons were developed in the 20th century. The corrosion of rebars or prestressed tendons that are used to increase the carrying capacity of a concrete structure is a severe problem. Corrosion is referred to as the "disaster of the century." The corrosion of prestressed tendons may be more severe in a prestressed concrete structure than a regular reinforced concrete structure because prestressed tendons bear higher stresses over a smaller area [6-10]. Because of corrosion damage or hydrogen embrittlement, high-strength rebars exhibit greater brittleness. As a result, the corrosion damage of prestressed tendons may lead to the collapse of a bridge structure without any early warning. Over the past several decades, the span of prestressed concrete structural members has continuously increased. Prestressed concrete structural members are mainly used in bridges and buildings, including cable-stayed bridges, offshore structures, nuclear reactor vessels, large commercial and industrial buildings, parking garages, and structures used for other purposes. 
Additionally, people have gradually realized that the longterm service life of existing building structures is reduced because of environmental factors.

After a certain number of years of service, the performance curve of a concrete bridge will monotonically decrease because of external environmental factors and material deterioration. The rebars distributed closest to the structure surface beneath the protective cover layer of concrete are the most prone to corrosion. Corrosion of the distributed rebars will result in delamination of the cover layer of concrete, which results in a decrease in the thickness of the actual cover layer of the main prestressed bars in the prestressed concrete beam and a reduction in the durability of the bridge [11-13]. Therefore, research on the effect of the distribution of corroded rebars on the stress field in the surrounding concrete can provide information about changes in the effective protective layer of the main rebar after a bridge durability problem occurs and provide quantified data for studying the durability or even safety of the structure.

\section{Analytical Method}

The finite element method (FEM) is extensively used to analyze the stress field in concrete. To verify concrete damage resulting from rebar corrosion, a typical model used for the hole expansion test is selected for this study. A finite element program is used to perform a process simulation of a specimen. The change in the stress field in the protective layer of the specimen with a change in the radial expansion displacement is simulated. The cracking trend is predicted, which is compared with experimental results. Previous studies have demonstrated the feasibility of using the FEM for rebar simulation [14-17].

How to represent cracks is always a key issue in nonlinear finite element analyses of concrete materials. Cracking under tensile stress is an important factor in nonlinear analysis of concrete materials. Three main methods in ANSYS SOLID 65 for representing concrete cracks are as follows: (1) a single crack is represented by the edge of an element; (2) a single crack is represented by fracture mechanics; and (3) the cracks are represented by dispersing them inside the elements.

There are a couple of approaches for performing an FEM simulation of the damage to concrete caused by volume expansion induced by corrosion of rebar. One approach is performed by simulating the corrosion of the rebars based on the temperature expansion rings at the reserved rebar holes. Alternatively, an analysis of the stress field or strain field in the vicinity of the protective cover layer in the periphery of a concrete specimen with corroded rebars can be performed by simulating the corrosion-induced uniform expansion of the rebars through the application of a radial pressure or a radial displacement.

This study adopts the following technical approach. (1) Based on the simulation of the corrosion-induced uniform expansion of a rebar by applying a radial displacement, the effect of the corrosion-induced expansion of a single rebar on the stress and strain fields in the protective cover layer of the surrounding concrete is simulated by loading a single hole under different conditions. (2) The simulation results

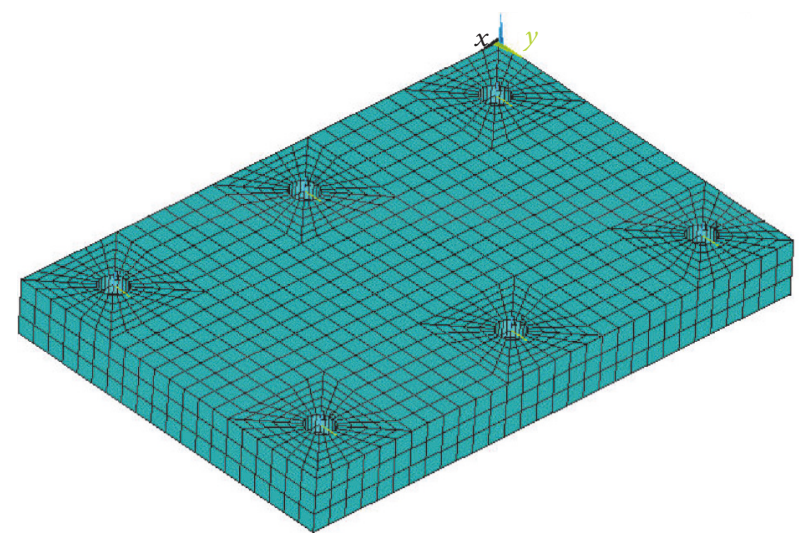

FIGURE 1: Finite element model and its mesh generation.

are compared with published experimental results [15, 17]. (3) The effect of the corrosion-induced expansion of multiple rebars on the stress and strain fields in the protective layer of the surrounding concrete is simulated by loading six holes under different conditions.

Researchers have studied the theories and processes of electrochemical corrosion testing and analyzed the phenomena that occur during the testing processes and their causes $[15,18,19]$. The following conclusions have been obtained.

(1) When microcracks appear in the protective cover layer of a concrete specimen with corroded rebars, oblique cracks appear earlier than vertical cracks. However, during the crack propagation process, the vertical cracks propagate at significantly higher rates than the oblique cracks. In addition, as a vertical crack further propagates, the other cracks in the vicinity of the same rebar will propagate at reduced rates, stop propagating, or even close up.

(2) After the initial cracks appear, it is more difficult for more cracks to appear when the protective cover layer is the thicker and the tensile strength of the concrete is the higher.

\section{Corrosion-Induced Expansion Simulation Method Verification}

A concrete model with a dimension of $300 \mathrm{~mm} \times 200 \mathrm{~mm} \times$ $300 \mathrm{~mm}$ is selected. The rebar holes have a diameter of $16 \mathrm{~mm}$, and the spacing between two adjacent rebar holes is $120 \mathrm{~mm}$. The protective cover layer is $22 \mathrm{~mm}$ thick. The concrete has the same strength as a grade C50 concrete. In addition, the values of the tensile strength, compressive strength, elastic modulus, and Poisson's ratio of the concrete satisfy the specifications.

The solid elements near the rebar holes are irregular, while all other solid elements are $1 \mathrm{~mm}^{3}$ cubes. A finite element model with a $30 \mathrm{~mm}$ thick middle section is selected. Figure 1 shows the dimension and mesh generation of the selected model. It is assumed that all the elements at the bottom of the concrete model are consolidated. The calculation results show that the middle section is relatively far away from the bottom, and consequently, there is basically no boundary effect. 


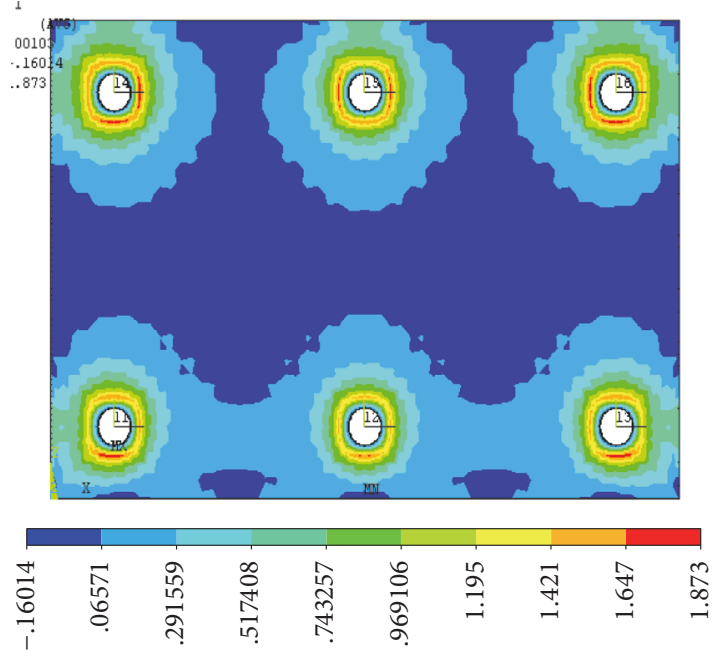

FIgURE 2: Principal tensile stress when the displacement resulting from the corrosion-induced expansion reaches $0.001 \mathrm{~mm}$.

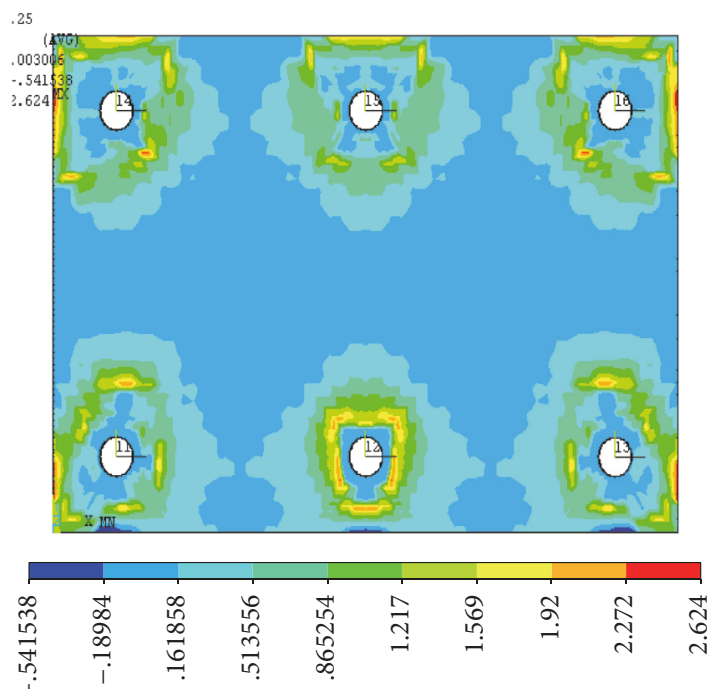

Figure 3: Principal tensile stress when the displacement resulting from the corrosion-induced expansion reaches $0.0025 \mathrm{~mm}$.

Loading Method. The corrosion-induced expansion is assumed to be uniform. A cylindrical coordinate system is set at the centre of each rebar hole. The nodes surrounding each hole in the original Cartesian coordinate system are transformed to nodes in the cylindrical coordinate system through rotation. Each node undergoes a displacement.

Figures 2-5 show the stress nephogram at each hole. When the displacement resulting from the corrosioninduced expansion is relatively small, the principal tensile stress gradually decreases from the inside to the outside of each hole. As the displacement increases to $0.0025 \mathrm{~mm}$, the maximum tensile stress, which occurs in the corners, reaches as high as $2.624 \mathrm{MPa}$ (as shown in the stress nephogram in Figure 3), which indicates that the corners are more susceptible to the effect of rebar corrosion compared with other

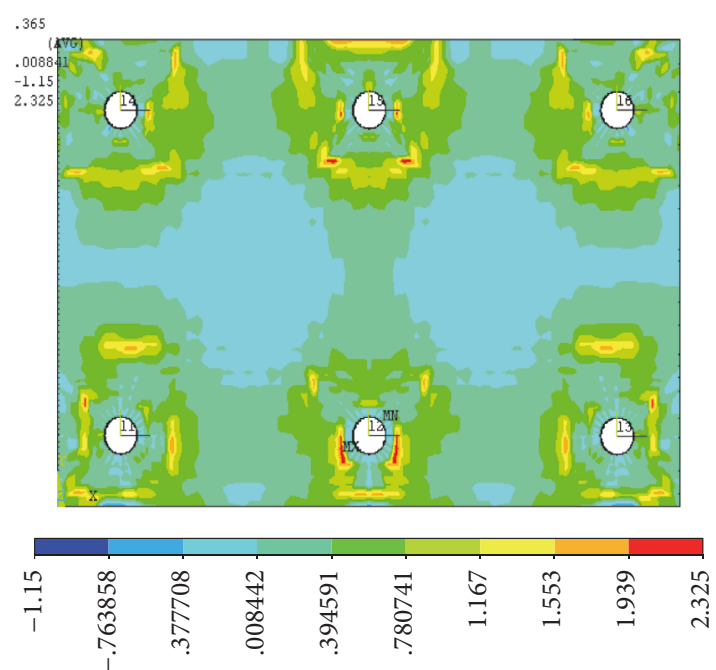

Figure 4: Principal tensile stress when the displacement resulting from the corrosion-induced expansion reaches $0.00365 \mathrm{~mm}$.

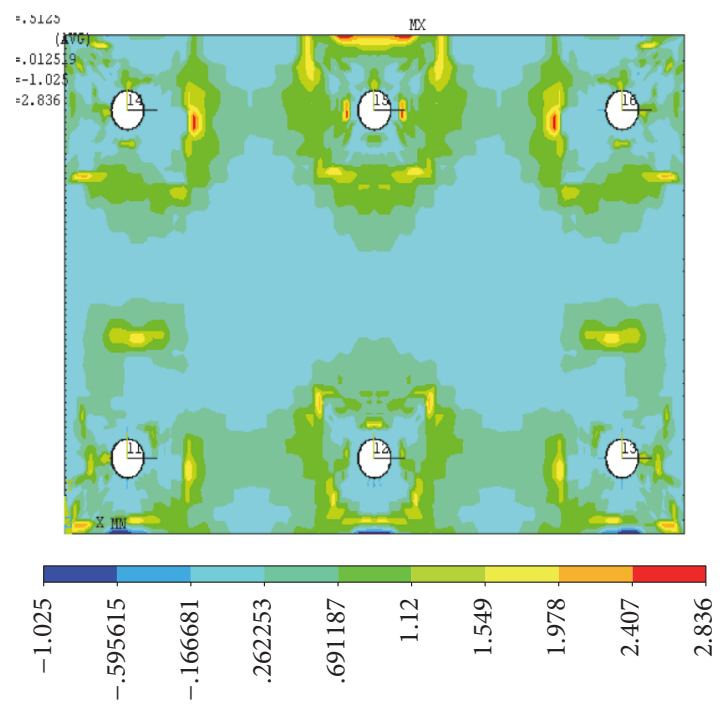

FIGURE 5: Principal tensile stress when the displacement resulting from the corrosion-induced expansion reaches $0.00513 \mathrm{~mm}$.

locations. Studies $[14,20]$ have shown that the extent of rebar corrosion in the corners is approximately 1.5 times greater than in other locations. As the displacement resulting from the corrosion-induced expansion increases to $0.0025 \mathrm{~mm}$, the principal tensile stress at the edges of the protective layer in the middle section gradually increases. As the corrosioninduced expansion displacement increases to $0.00513 \mathrm{~mm}$, the principal tensile stress at the edges of the protective layer in the middle section increases to $2.836 \mathrm{MPa}$, at which point the protective cover layer surface cracks.

Regarding the principal tensile strain in the surrounding concrete when the displacement resulting from the corrosion-induced expansion reaches 0.001 and $0.00513 \mathrm{~mm}$, respectively, the effect of rebar corrosion on the direction of the concrete cracks can be observed, and the maximum principal tensile strain reaches 0.0036 . 


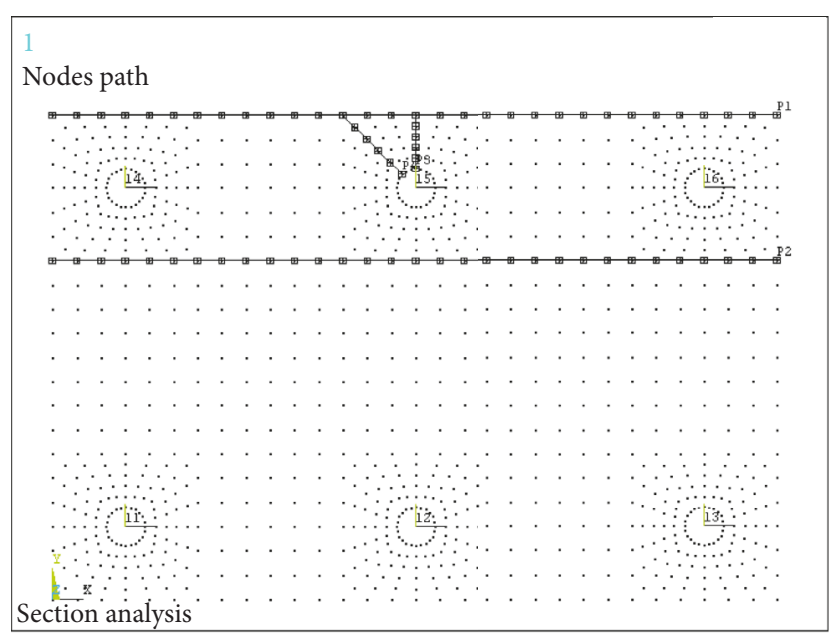

Figure 6: Schematic diagram of paths P1-P4.

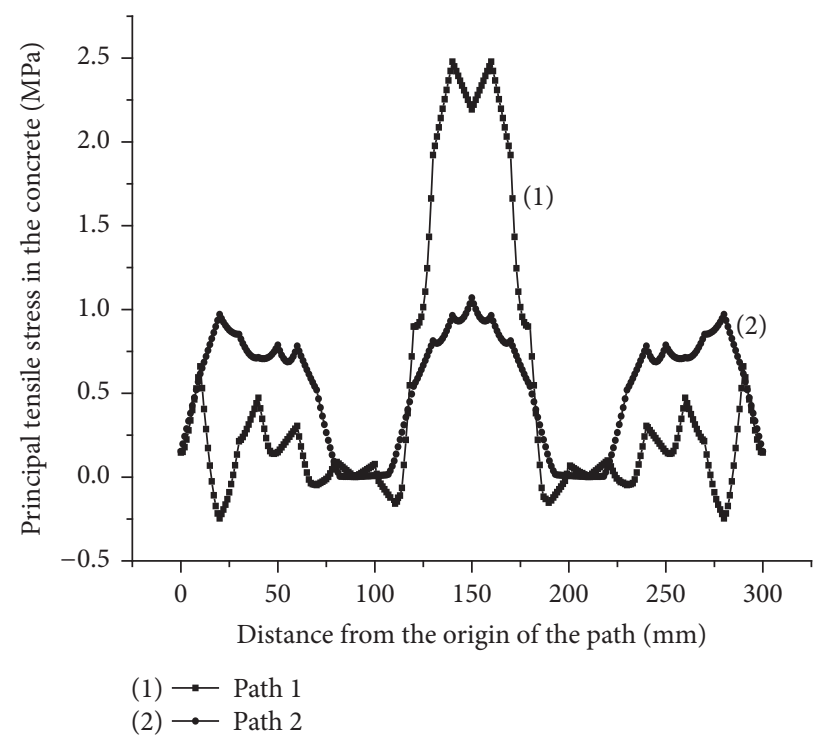

FIGURE 7: Distribution of the principal tensile stress along the edges of the protective cover layer.

In Figures 6 and 7 (definition of two paths, P1 and P2, as well as the relevant results), the distribution of the principal tensile stress along the outer edges of the protective layer is shown. In Figures 6 and 8 (definition of another two paths, P3 and P4, as well as the relevant results), the distributions of the principal tensile stress in the direction perpendicular to the boundary and the direction at an angle of $45^{\circ}$ with the boundary, respectively, are shown.

Through calculations, it is determined that a preapplication of a compressive load of $0.6228 \mathrm{MPa}$ and a preapplication of a displacement of $0.005125 \mathrm{~mm}$ on a rebar hole have similar effects on the stress field in the surrounding concrete.

Based on the analysis of the distribution of the stress field in the concrete resulting from the rebar corrosion-induced expansion using the FEM, the trend for the protective layer of the concrete cracks is consistent with experimental observations.

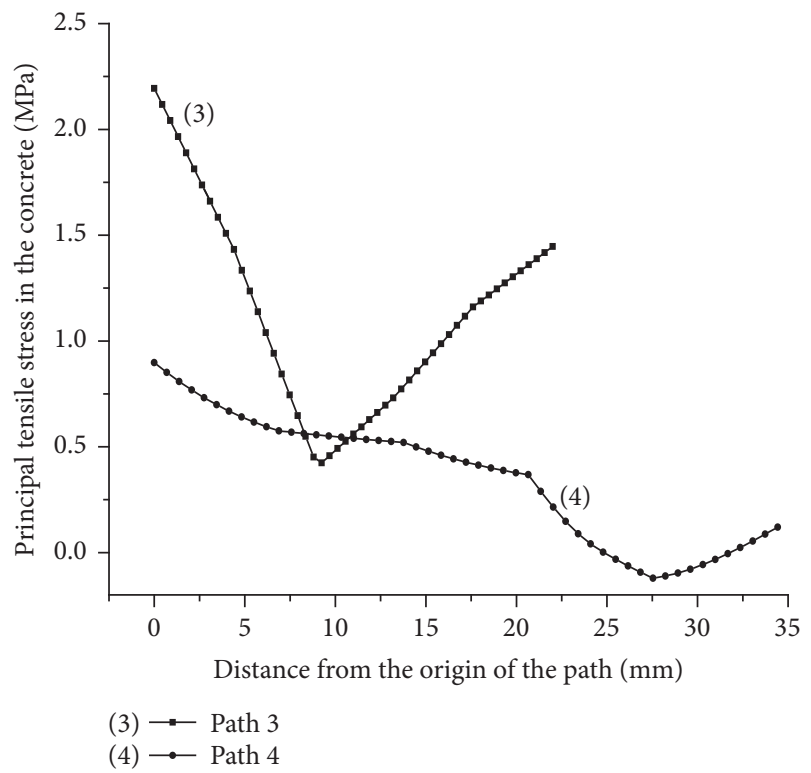

FIGURE 8: Distribution of the principal tensile stress in the direction perpendicular to the boundary and the direction at an angle of $45^{\circ}$ with the boundary.

\section{Parameter Sensitivity Analysis}

Concrete is always under stress when in use. To analyze the effect of rebar corrosion on the surrounding stress field under stress-inducing loads, five compressive stress conditions $(0$, $5,10,15$, and $20 \mathrm{MPa}$ ) are selected. These five conditions are selected because the current Design Specification for Reinforced Concrete for Highways and Prestressed Concrete Bridges (Version 7.1.5) requires that the compressive stress in the flexural concrete members of a prestressed concrete structure at normal cross-sections when in use should conform to the requirement for the maximum allowable compressive stress in concrete commonly used in bridge structures, where the compressive stress should be less than $20 \mathrm{MPa}$.

According to Saint Venant's Principle, a prism with a volume of $116 \times 116 \times 600 \mathrm{~mm}^{3}$ is selected and subjected to a loading test (Figure 9).

Based on the analysis method described in Section 3, a protective layer that is $50 \mathrm{~mm}$ in thickness (commonly used in bridges) is selected to dynamically observe the effect of rebar corrosion on the stress field in the surrounding concrete. According to Saint Venant's Principle, the middle section $(300-400 \mathrm{~mm})$ is selected for analysis. The development of corrosion-induced rebar expansion is simulated based on the increase in the virtual displacement resulting from corrosion-induced rebar expansion to understand the effect of the increase in rebar corrosion on the stress field in the surrounding concrete. Here, the dead weight of the component is not taken into consideration. One end of the component is completely anchored because a load must be applied locally to the other end. To ensure the convergence of the loading process, steel plates are used to replace the elements at the end. A uniformly distributed load is directly applied to the elements at the end. 
TABLE 1: Maximum virtual rebar displacement under five prestress conditions.

\begin{tabular}{lcccc}
\hline Prestress $(\mathrm{MPa})$ & 0 & 5 & 10 & 15 \\
\hline $\begin{array}{l}\text { Maximum virtual displacement resulting } \\
\text { from corrosion-induced expansion }(\mathrm{mm})\end{array}$ & 0.00453 & 0.02812 & 0.03106 & 0.02947 \\
\hline
\end{tabular}

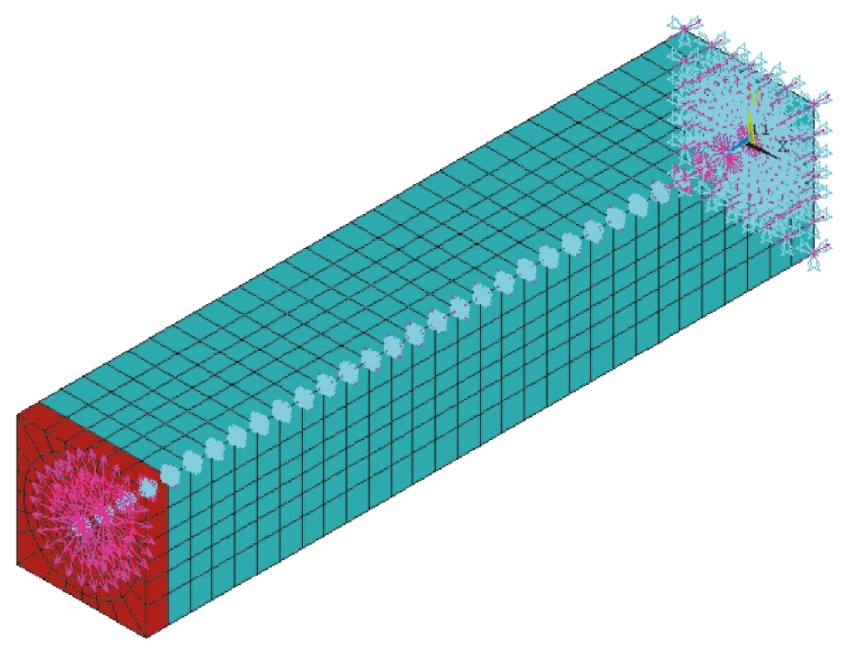

FIGURE 9: Beam segment model for simulating the displacement caused by corrosion-induced rebar expansion under stress.

Two load steps are incorporated into the complete process of analysis. First, the effect of prestressing on the concrete beam is simulated by applying a planar load to the concrete elements at the end, generating a corresponding compressive stress. Second, similar to the method used in Section 3, the effect of the expansion of the corrosion product on the surrounding stress field is simulated by generating a virtual circumferential displacement to the rebar hole. The concrete collapses in local areas and thus is unloaded. The failure model is selected based on the maximum tensile stress criterion.

Based on Table 1, when the concrete is not prestressed, the virtual rebar displacement is very small. As a result, computational convergence is not achieved because of the overly large tensile stress near the rebar $(2.981 \mathrm{MPa})$. When the prestress effect is absent, damage occurs to the surrounding concrete when the virtual displacement resulting from corrosioninduced expansion reaches $0.00453 \mathrm{~mm}$, and consequently, the calculation fails to achieve convergence. When the concrete is prestressed under a load of $20 \mathrm{MPa}$, damage occurs to the surrounding concrete only when the virtual displacement resulting from corrosion-induced expansion reaches $0.04099 \mathrm{~mm}$ (almost 10 times that when the concrete is not prestressed), and calculation divergence occurs. The greater the maximum virtual displacement resulting from corrosioninduced expansion is, the greater the rebar corrosion is, that is, the longer it takes for the surrounding concrete to crack under this condition.

To understand crack formation in the surrounding concrete resulting from the pressure generated during the rebar

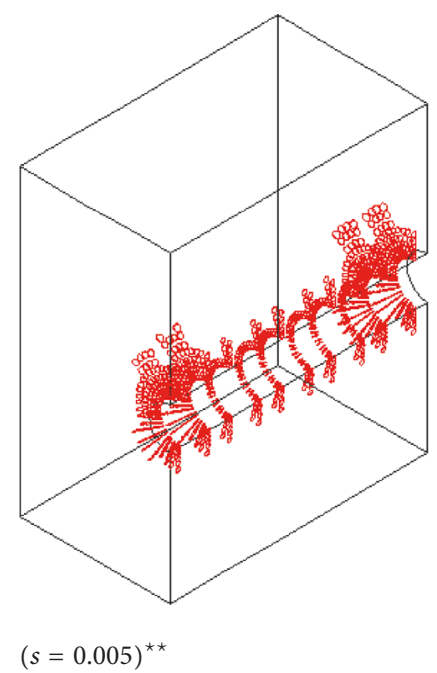

FIGURE 10: Displacement resulting from corrosion-induced expansion $=0.005 \mathrm{~mm}$.

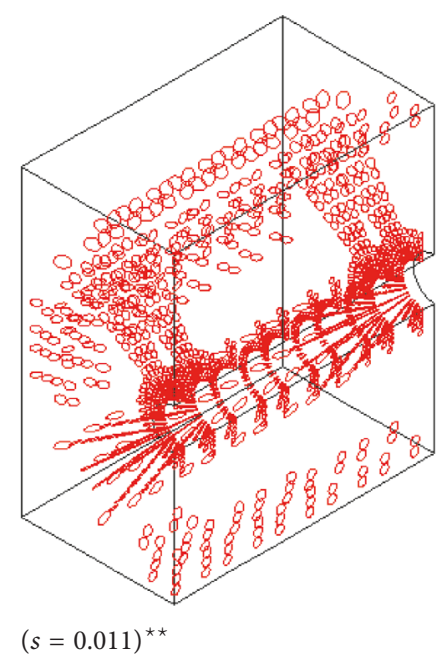

FIGURE 11: Displacement resulting from corrosion-induced expansion $=0.011 \mathrm{~mm}$.

corrosion process, the crack pattern formed during the corrosion-induced rebar expansion process is illustrated with the concrete prestressed under a compressive load of $20 \mathrm{MPa}$ as an example. Figures 10, 11, 12, and 13 show the crack pattern formed in the said concrete under various virtual rebar displacements resulting from corrosion-induced expansion.

When the corrosion-induced displacement reaches $0.035 \mathrm{~mm}$, cracks have already sufficiently developed. In 


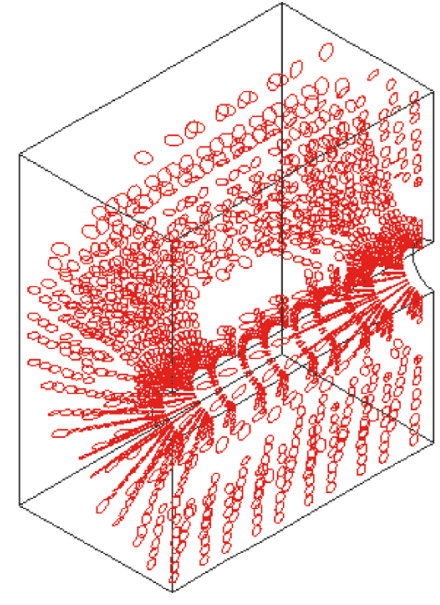

$(s=0.035)^{\star \star}$

FIGURE 12: Displacement resulting from corrosion-induced expansion $=0.035 \mathrm{~mm}$.

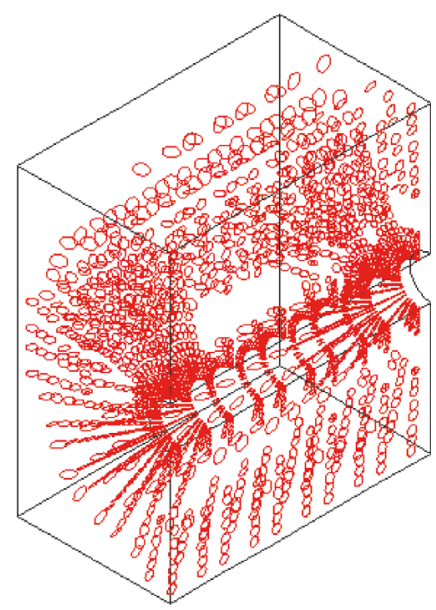

$(s=0.041)^{\star \star}$

FIGURE 13: Displacement resulting from corrosion-induced expansion $=0.041 \mathrm{~mm}$.

other words, when only the effect of the compressive prestress in the concrete on rebar corrosion is considered, the higher the compressive prestress is and the more fully the material is utilized. Crack directions can be observed from the cross-sectional views. Cracks near the rebar hole are perpendicular to the rebar surface, whereas theoretically, when a rebar hole reaches the external edge of the protective layer, cracks are no longer perpendicular to the rebar hole, but instead, they become perpendicular to the external edge of the protective layer.

Figure 14 shows the specific locations of elements 1-4 on the cross-section. Figures 15 and 16 show the load-principal tensile stress time-history curve for elements $1-4$, respectively.

The average principal tensile stress in the nodes of each element is selected. In reality, the principal tensile stress in some nodes already exceeds the standard axial tensile

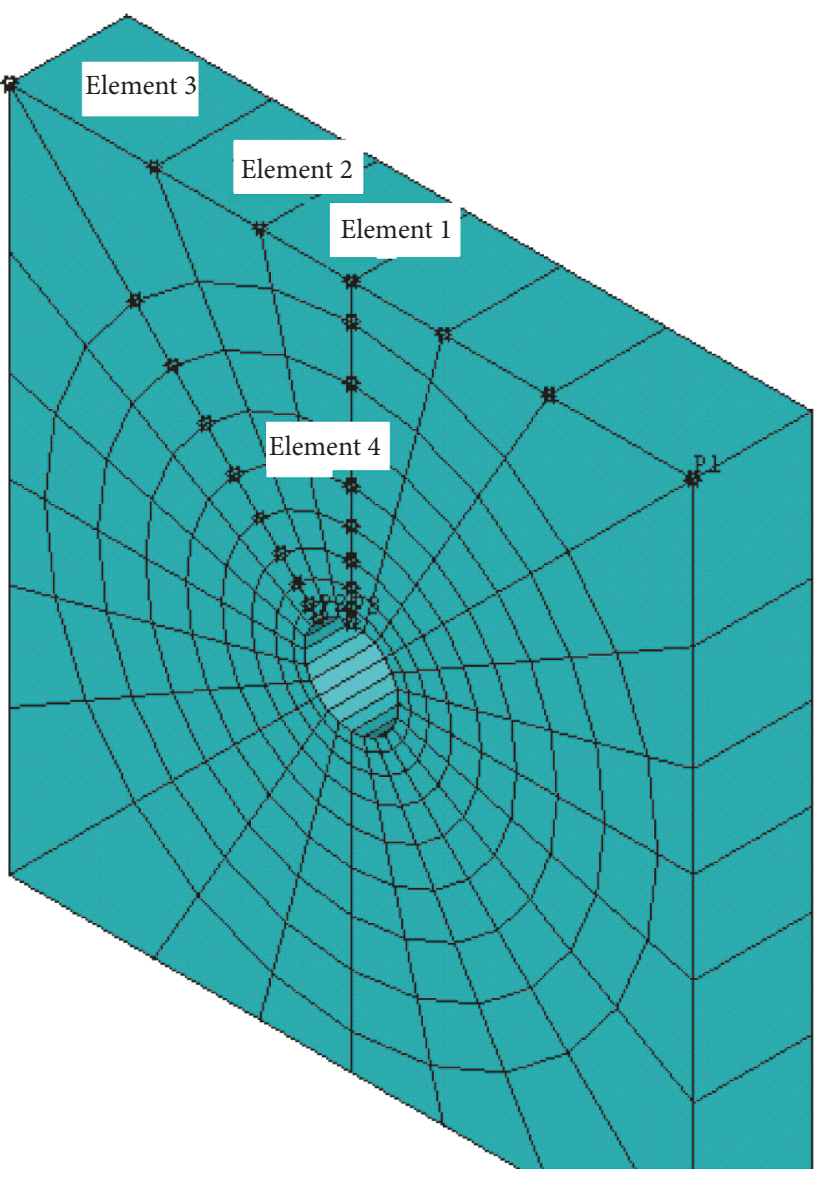

FIGURE 14: Locations of elements 1-4.

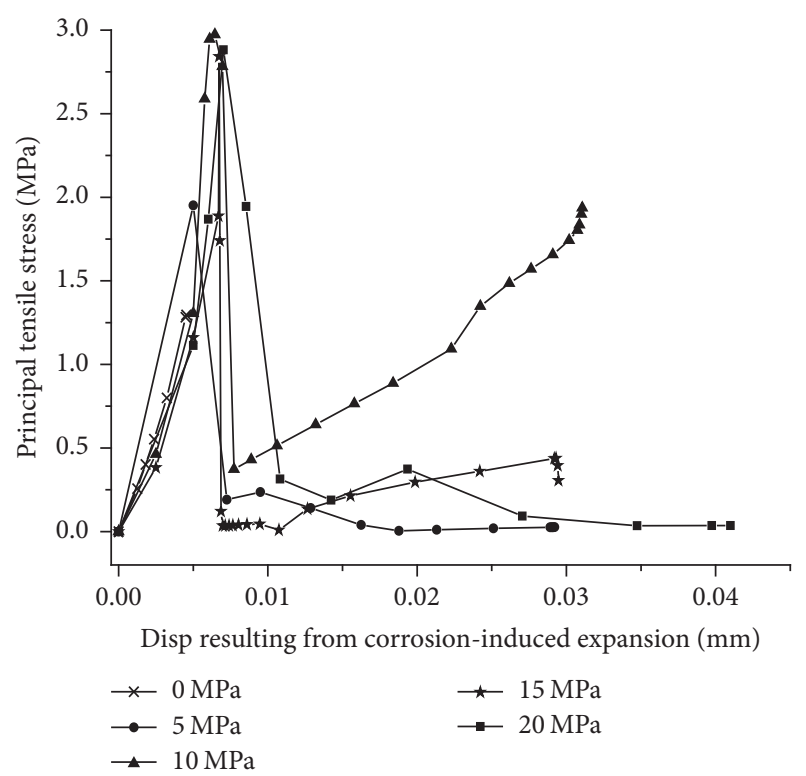

FIGURE 15: Load-principal tensile stress time-history curve for element 1. 


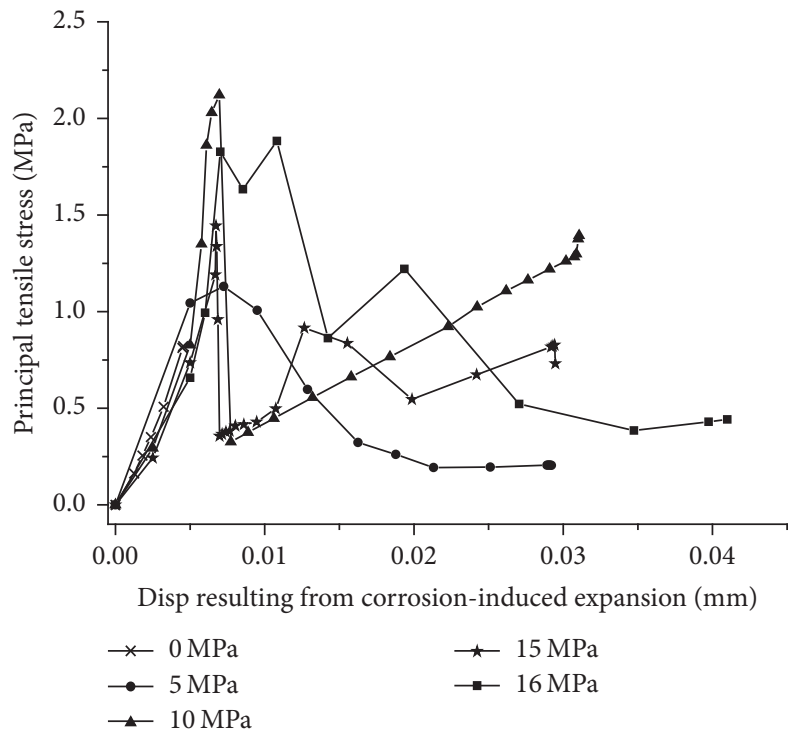

FIGURE 16: Load-principal tensile stress time-history curve for element 2 .

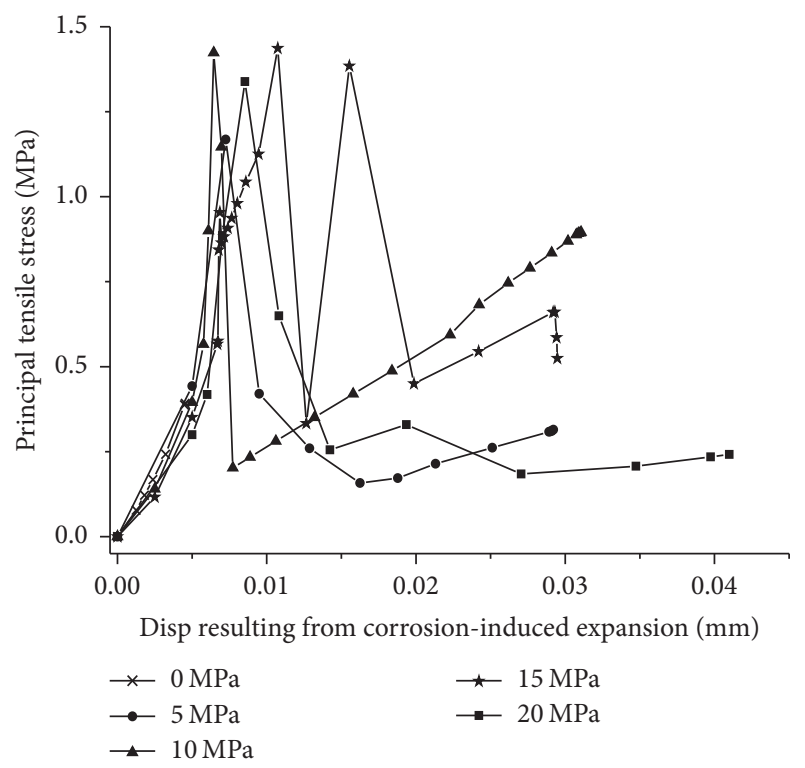

FIGURE 17: Load-principal tensile stress time-history curve for element 3.

strength. Based on Figures 15-18, the principal tensile stress in element 1 reaches its peak value at nearly $3 \mathrm{MPa}$ when the virtual displacement resulting from corrosion-induced expansion reaches approximately $0.005 \mathrm{~mm}$, after which stress redistribution occurs and the tensile stress decreases rapidly. As the displacement resulting from corrosion-induced expansion increases, the principal tensile stress decreases to $0-0.5 \mathrm{MPa}$ in all cases except the case in which the concrete is prestressed under a compressive load of $10 \mathrm{MPa}$.

For element 3 , the time when the maximum principal tensile stress occurs varies slightly between different concrete specimens, when the displacement resulting from corrosioninduced expansion reaches $0.005-0.015 \mathrm{~mm}$. The load-principal tensile stress time-history curves of the concrete exhibit

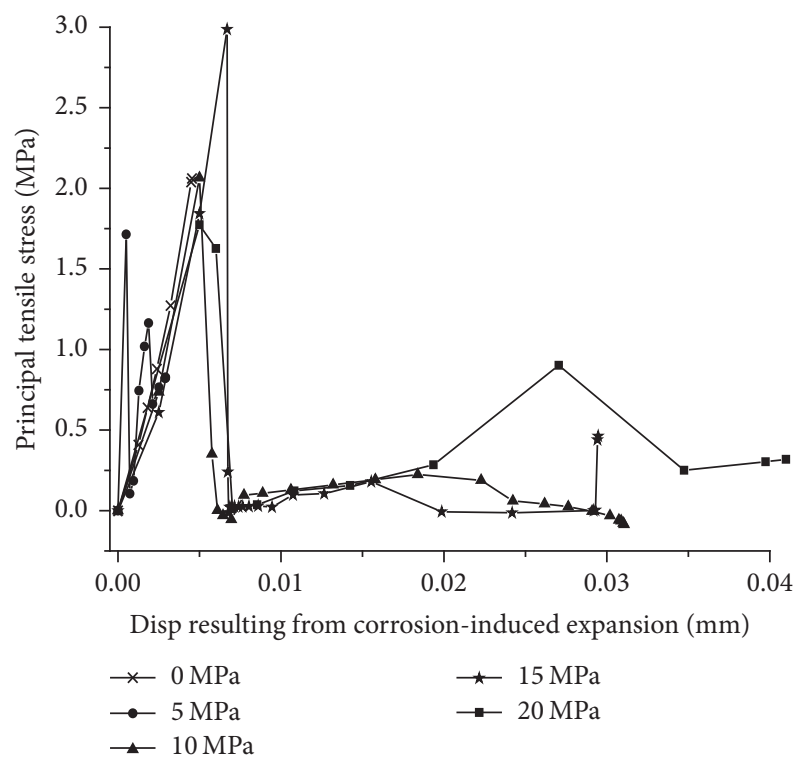

FIgURE 18: Load-principal tensile stress time-history curve for element 4.

trends that are essentially similar in various elements. Based on the load-principal tensile stress time-history curve for each element, rebar corrosion has a significant impact on the stress field in the surrounding concrete, and stress redistribution in the stress field is conspicuous.

Figures 19-27 show a comparison of the principal tensile stress generated along paths 1-3 in concrete specimens prestressed under various loads when the displacement resulting from corrosion-induced expansion reaches $0.005,0.01$, and $0.022 \mathrm{~mm}$, respectively.

For path 1, when the virtual displacement resulting from corrosion-induced expansion is very small, the principal tensile stress at the midpoint of path 1 is the highest, and its peak value reaches $1.0-2.5 \mathrm{MPa}$. As the displacement resulting from corrosion-induced expansion increases, the principal tensile stress at the midpoint of path 1 decreases sharply to $0-0.5 \mathrm{MPa}$ (the unprestressed concrete specimen is excluded from consideration because the calculation is divergent). This indicates that when concrete is prestressed under a low compressive load, the rebar corrosion-induced expansion force can easily result in the generation of a relatively high principal tensile stress in the surrounding concrete, which in turn results in crack formation, leading to a calculation divergence. When the virtual displacement resulting from corrosion-induced expansion is relatively large, the principal tensile stress tends to be low at the midpoint of path 1 and relatively high at the point $1 / 4$ of the whole length of path 1 relative to the start point of path 1 and the point $3 / 4$ of the whole length of path 1 , measured similarly. The results concerning path 2 show that when the virtual displacement is relatively small, the peak value of the principal tensile stress occurs at a location 35-70 $\mathrm{mm}$ away from the start point of path 2; as the virtual displacement increases, the location where the peak value of the principal tensile stress occurs changes, and the peak value also decreases. Path 3 is perpendicular to the edge 


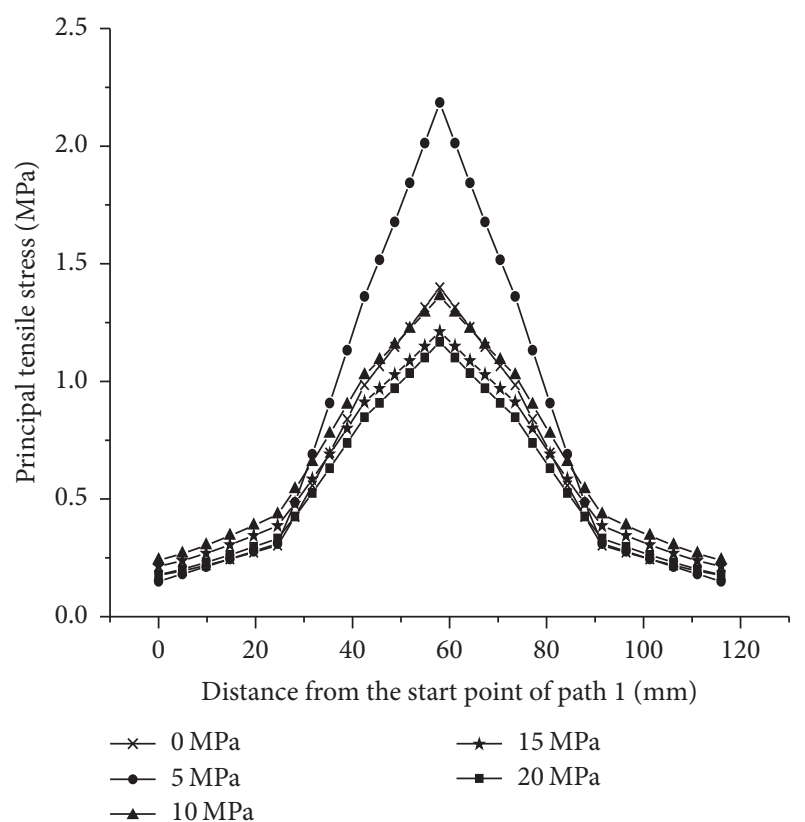

FIGURE 19: Comparison of the principal tensile stress generated along path 1 from corrosion-induced expansion when the displacement resulting from corrosion-induced expansion reaches $0.005 \mathrm{~mm}$.

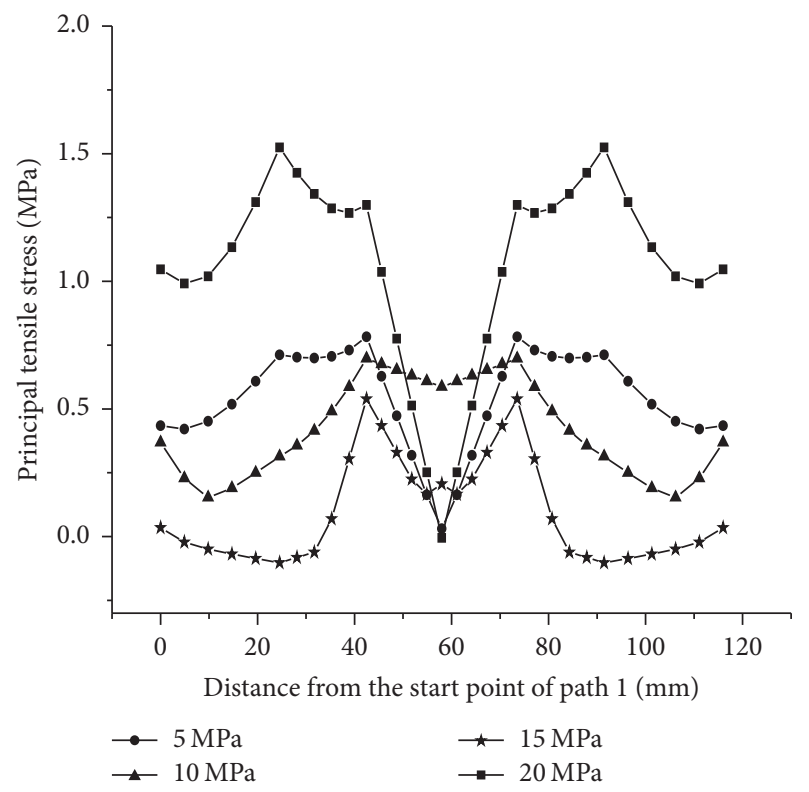

FIGURE 20: Comparison of the principal tensile stress generated along path 1 from corrosion-induced expansion when the displacement resulting from corrosion-induced expansion reaches $0.01 \mathrm{~mm}$.

of the protective layer. When the displacement resulting from corrosion-induced expansion is relatively small, the peak value of the principal tensile stress occurs at a location near the rebar hole; as the displacement resulting from corrosioninduced expansion increases, the location where the peak

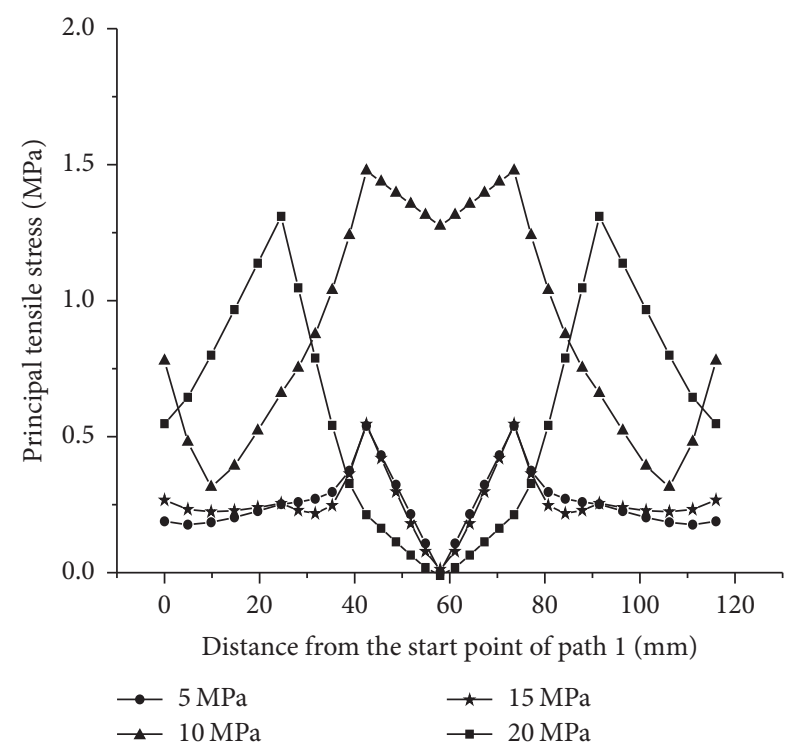

FIGURE 21: Comparison of the principal tensile stress generated along path 1 from corrosion-induced expansion when the displacement resulting from corrosion-induced expansion reaches $0.022 \mathrm{~mm}$.

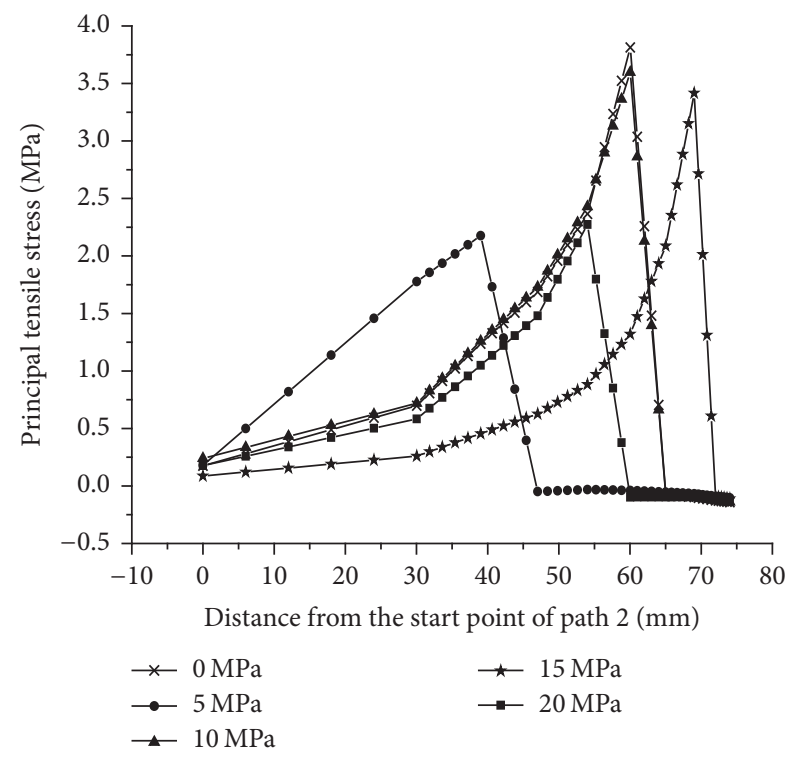

FIGURE 22: Comparison of the principal tensile stress generated along path 2 from corrosion-induced expansion when the displacement resulting from corrosion-induced expansion reaches $0.005 \mathrm{~mm}$.

value of the principal tensile stress occurs shifts toward the edge of the protective layer. To more clearly and dynamically observe the change in the principal tensile stress in the stress field in the surrounding concrete resulting from rebar corrosion, principal tensile stress nephograms are produced (Figures 28-31). The concrete specimen prestressed under a load of $10 \mathrm{MPa}$ is selected for illustration. 


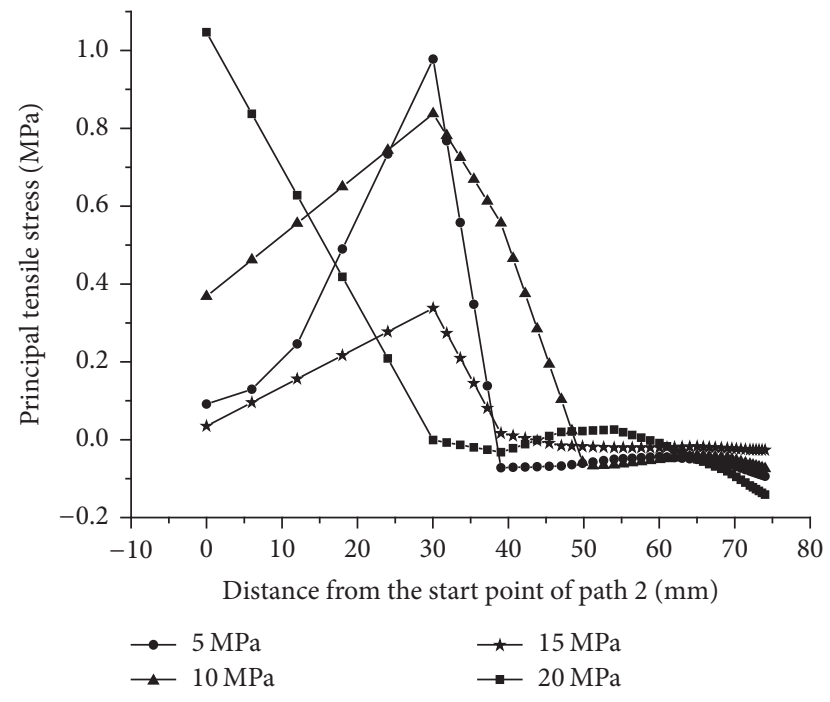

Figure 23: Comparison of the principal tensile stress generated along path 2 from corrosion-induced expansion when the displacement resulting from corrosion-induced expansion reaches $0.01 \mathrm{~mm}$.

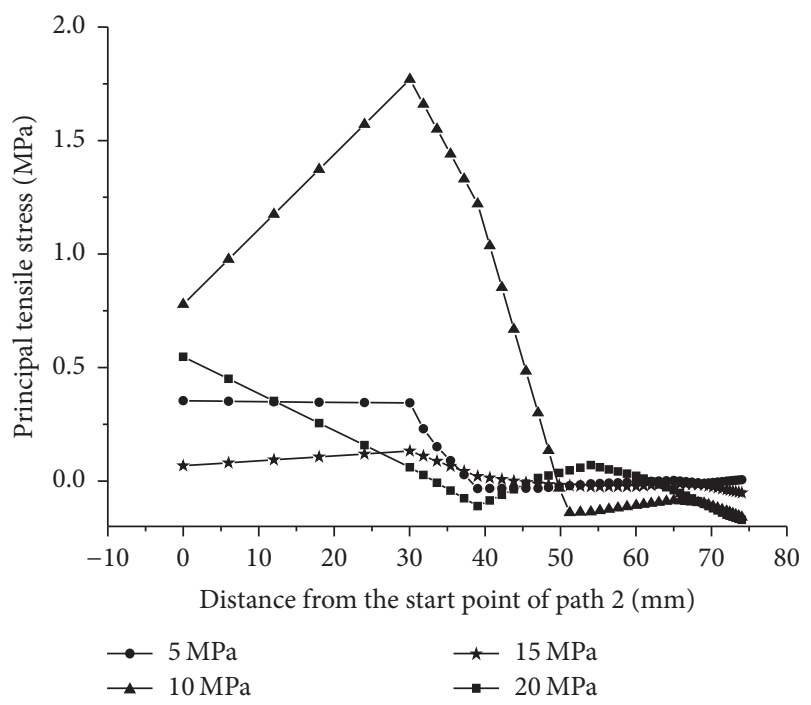

FIGURE 24: Comparison of the principal tensile stress generated along path 2 from corrosion-induced expansion when the displacement resulting from corrosion-induced expansion reaches $0.022 \mathrm{~mm}$.

Figures 33-40 show the principal tensile stress in the concrete specimen prestressed under a load of $10 \mathrm{MPa}$ along the eight paths shown in Figure 32 when the displacement resulting from corrosion-induced expansion reaches $0.031 \mathrm{~mm}$, respectively. Evidently, the principal tensile stresses along paths $1-3$ reach their maximum values immediately above the rebar hole and increase with decreasing distance from the external edge of the protective layer. In comparison, the maximum principal tensile stresses along paths $4-8$ occur at varying locations, and the principal tensile stress along each of these paths is relatively small.

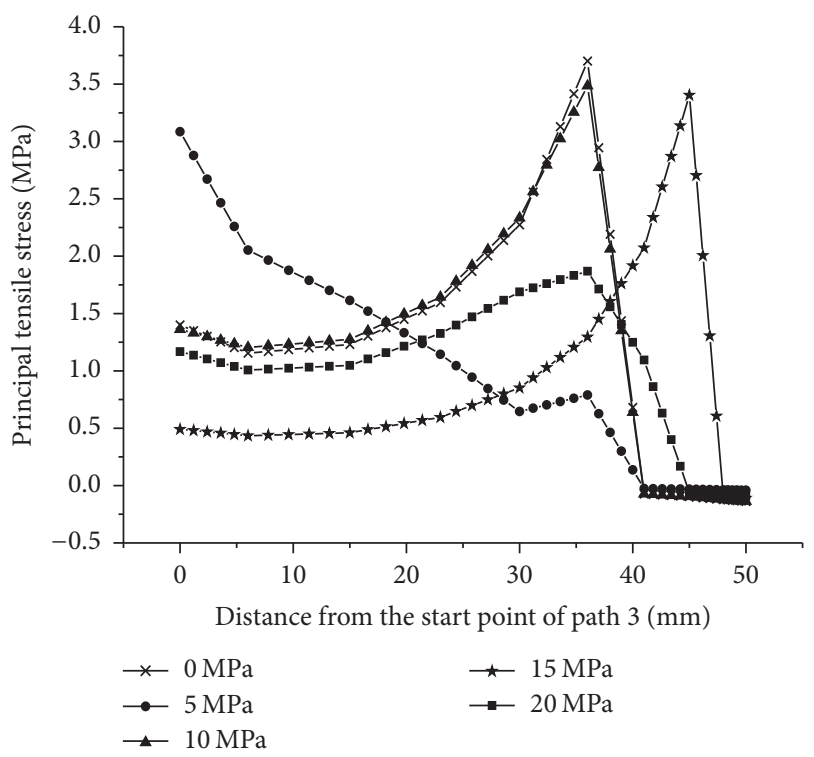

FIgURE 25: Comparison of the principal tensile stress generated along path 3 from corrosion-induced expansion when the displacement resulting from corrosion-induced expansion reaches $0.005 \mathrm{~mm}$.

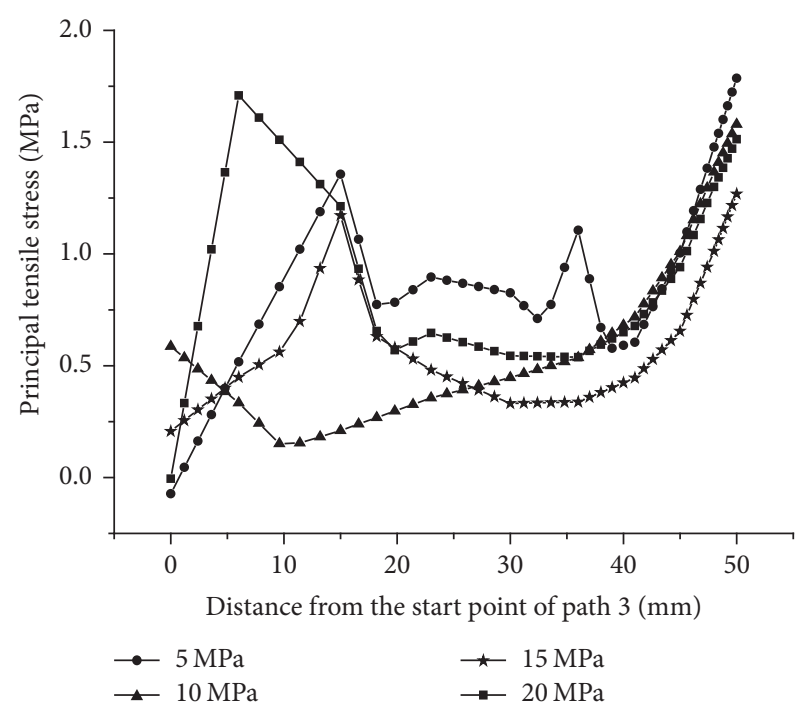

FIGURE 26: Comparison of the principal tensile stress generated along path 3 from corrosion-induced expansion when the displacement resulting from corrosion-induced expansion reaches $0.01 \mathrm{~mm}$.

\section{FEM Analysis of the Stress Resulting from Corrosion-Induced Expansion Based on a Bridge Beam Segment Model}

To understand postcorrosion stress fields in concrete constituting bridge segments under actual conditions, half of an actual bridge is used as an example to investigate the effect of porous ordinary rebar corrosion on concrete and its deformation. 


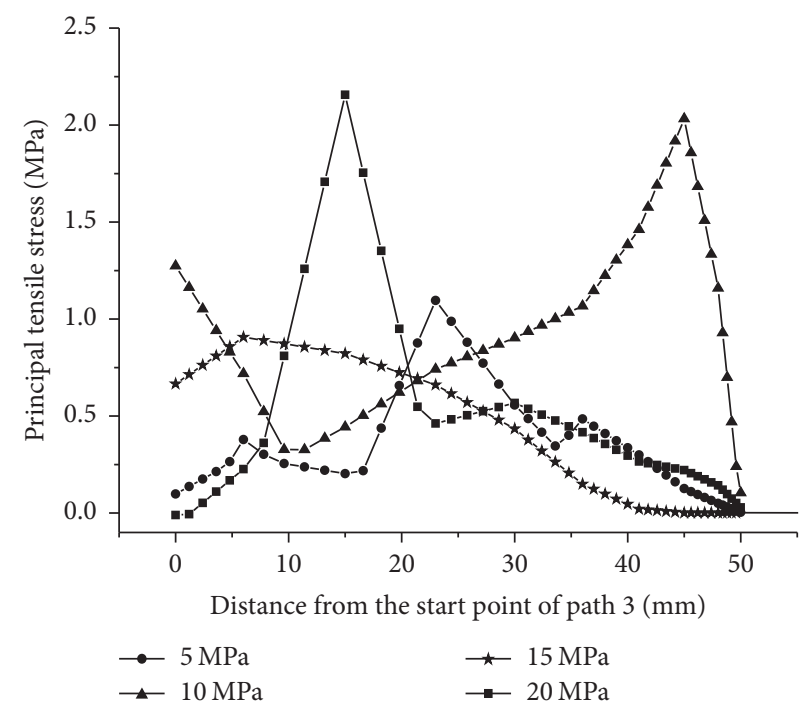

Figure 27: Comparison of the principal tensile stress generated along path 3 from corrosion-induced expansion when the displacement resulting from corrosion-induced expansion reaches $0.022 \mathrm{~mm}$.

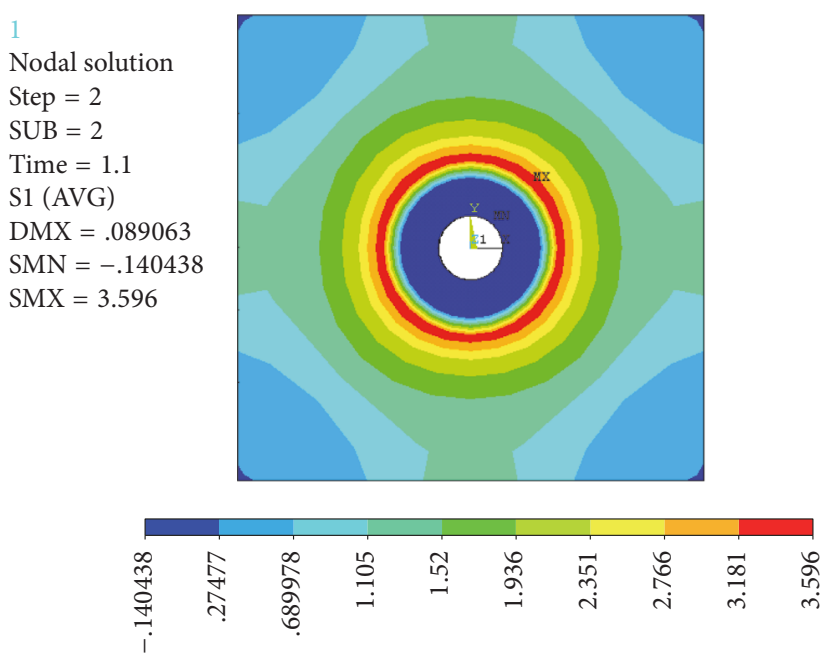

Figure 28: Principal tensile stress on the concrete specimen prestressed under a load of $10 \mathrm{MPa}$ when the displacement resulting from corrosion-induced expansion reaches $0.005 \mathrm{~mm}$.

Figure 41 shows the element mesh generation for the transverse cross-section of half of an actual bridge. The spacing between ordinary rebars is $150 \mathrm{~mm}$. The thickness of the protective layer is set to $40 \mathrm{~mm}$. To simplify the calculation process, it is assumed that corrosion holes are only formed in the outer protective layer and corrosion does not occur in the interior cavity of the box beam. A virtual rebar displacement in the beam resulting from rebar corrosion is applied in the same way as in previous sections. Additionally, it is assumed that the concrete is not prestressed and that lower edge consolidation is the boundary condition for the beam segment.

The tensile strength option is turned off, and the maximum tensile stress criterion is applied. When the displacement resulting from corrosion-induced expansion reaches
0.0471, the calculation cannot be converged because of the overly large tensile strain. Figure 42 shows the nephogram of the principal tensile stress in the surrounding concrete when the displacement resulting from corrosion-induced expansion reaches 0.0471 . The principal tensile stress is zonally distributed at the edge of the protective layer of the concrete. Corrosion-induced expansion failure of the concrete occurs when the principal tensile stress in the concrete exceeds its ultimate tensile strength.

\section{Conclusions}

(1) During the corrosion-induced rebar expansion process, internal defects impact the stress field in the concrete. 


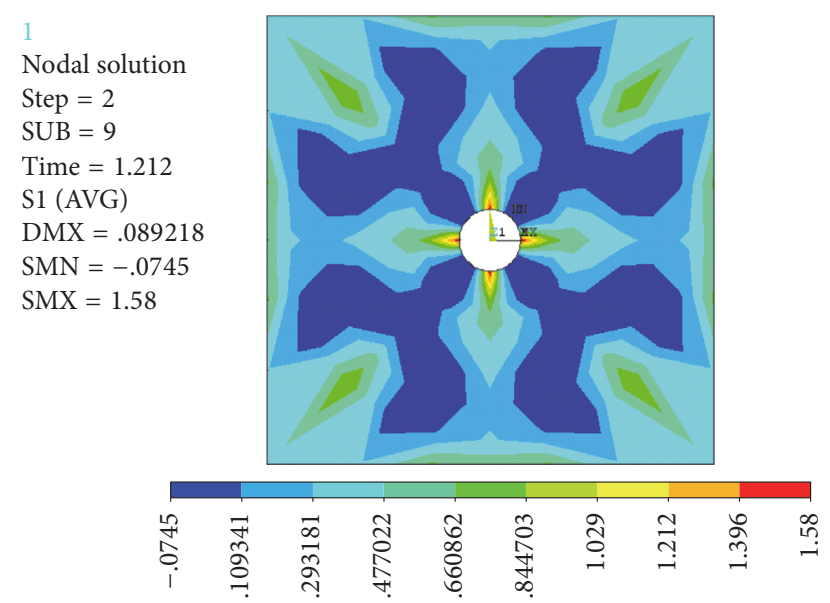

Figure 29: Principal tensile stress on the concrete specimen prestressed under a load of $10 \mathrm{MPa}$ when the displacement resulting from corrosion-induced expansion reaches $0.011 \mathrm{~mm}$.

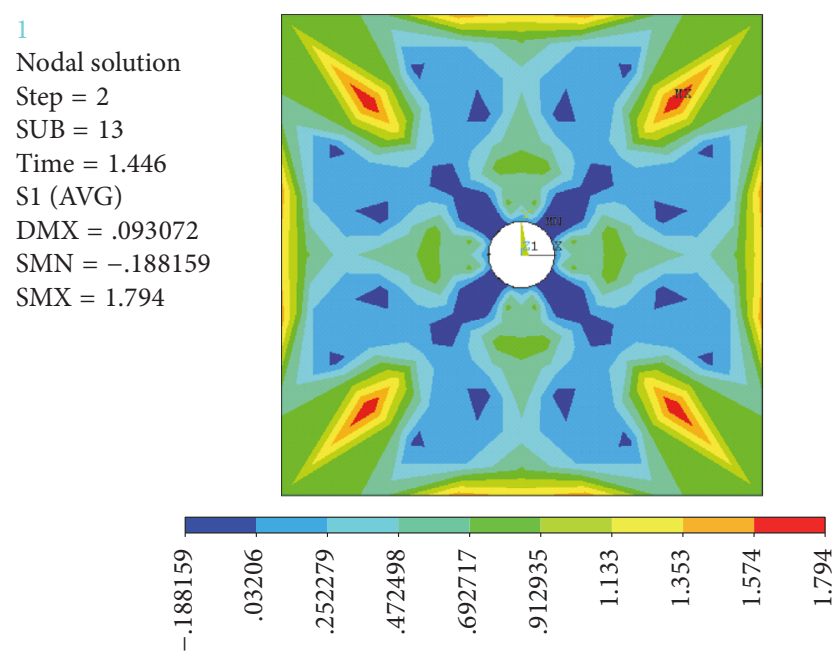

FIgURe 30: Principal tensile stress on the concrete specimen prestressed under a load of $10 \mathrm{MPa}$ when the displacement resulting from corrosion-induced expansion reaches $0.022 \mathrm{~mm}$.

Based on fracture mechanics theory, by introducing I-shaped microcavity cracks, the theoretical stress field distribution resulting from corrosion-induced expansion is derived. This stress field distribution can explain the randomness of crackinduced failures and sudden ruptures of some parts of the specimens observed during the experimental process. The comparison of the results of a case study and a theoretical study on a thick-walled cylinder based on elastic mechanics shows that internal microcrack defects have a significant impact on the stress field in the vicinity.

(2) Nephograms of the principal tensile stress and principal tensile strain in the concrete during the corrosioninduced rebar expansion process are obtained by transforming the volume expansion caused by the corrosion product into a virtual radial displacement that directly acts on the edge of the rebar hole to simulate the development of cracks

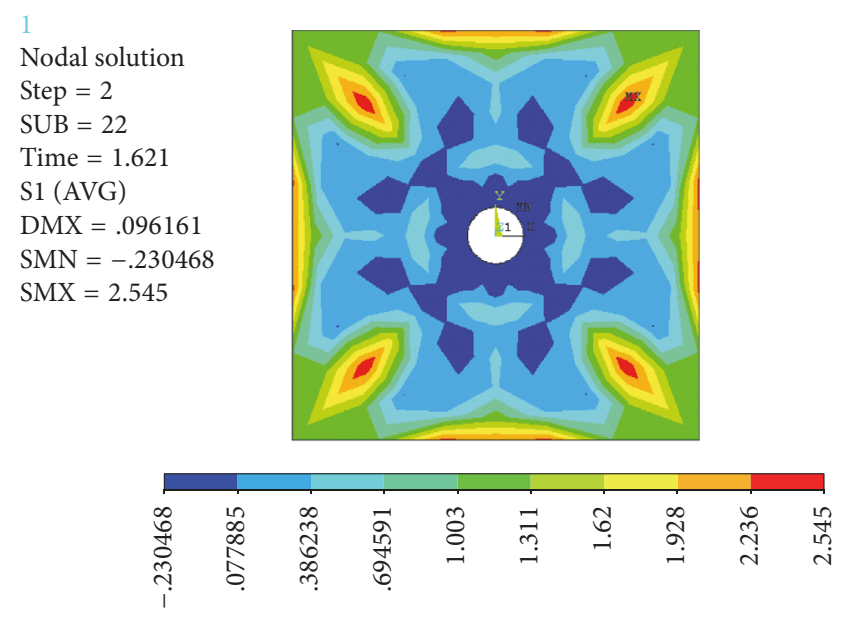

FIGURE 31: Principal tensile stress on the concrete specimen prestressed under a load of $10 \mathrm{MPa}$ when the displacement resulting from corrosion-induced expansion reaches $0.031 \mathrm{~mm}$.

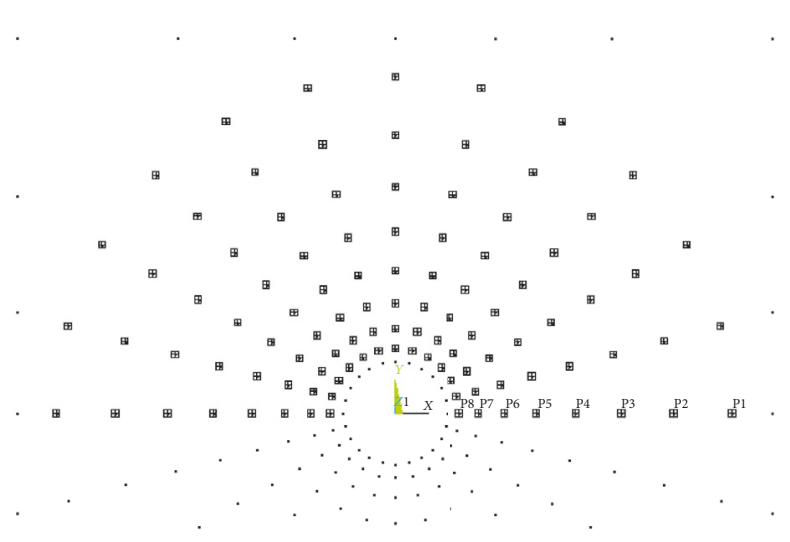

FIgURE 32: Definition of paths 1-9.

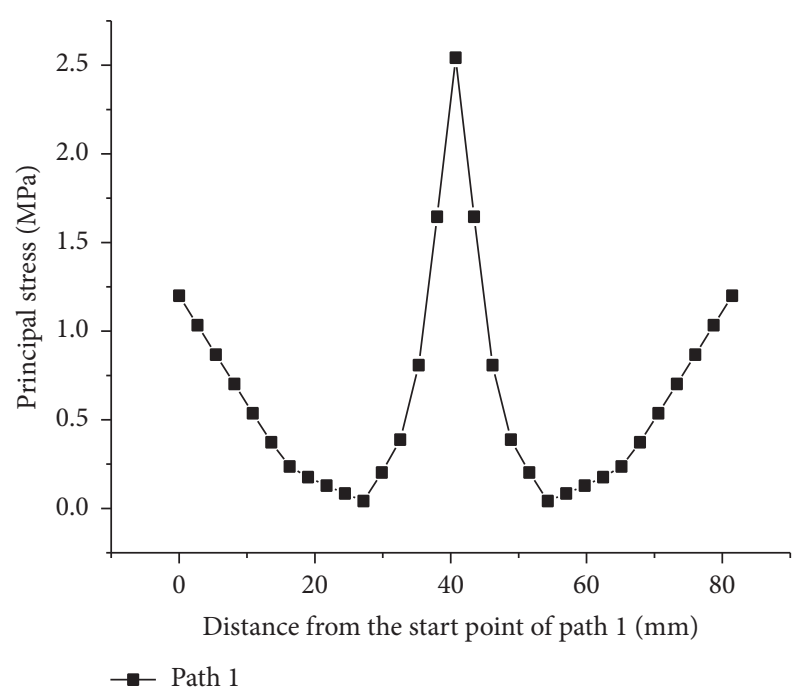

Figure 33: Principal tensile stress in the concrete specimen prestressed under a load of $10 \mathrm{MPa}$ when the displacement resulting from corrosion-induced expansion reaches $0.031 \mathrm{~mm}$. 


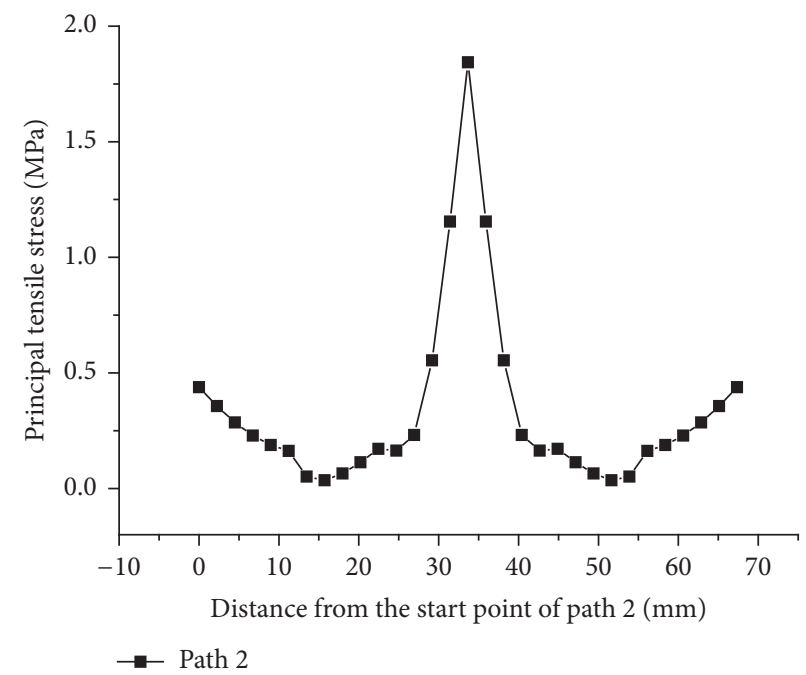

FIGURE 34: Principal tensile stress in the concrete specimen prestressed under a load of $10 \mathrm{MPa}$ when the displacement resulting from corrosion-induced expansion reaches $0.031 \mathrm{~mm}$.

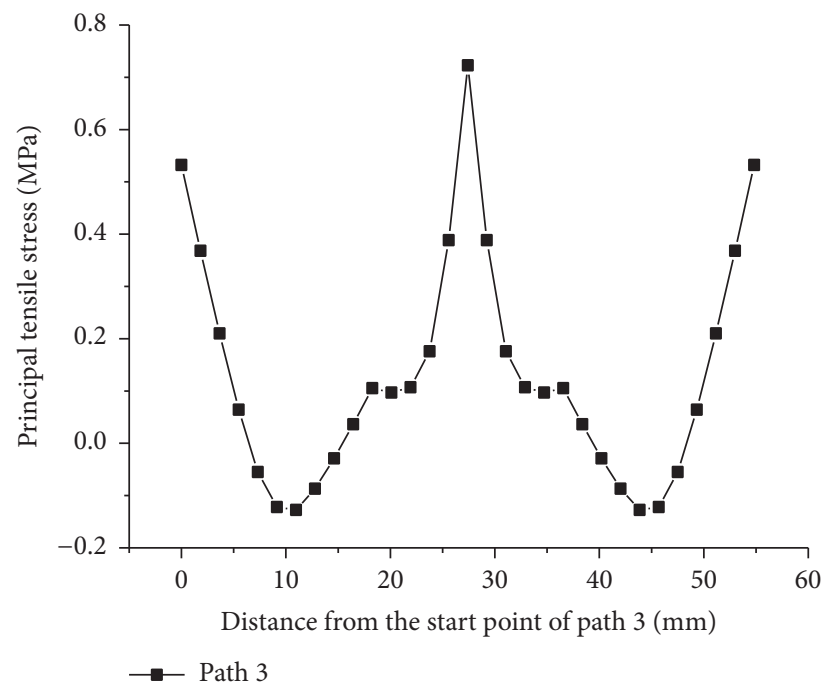

FIgURE 35: Principal tensile stress in the concrete specimen prestressed under a load of $10 \mathrm{MPa}$ when the displacement resulting from corrosion-induced expansion reaches $0.031 \mathrm{~mm}$.

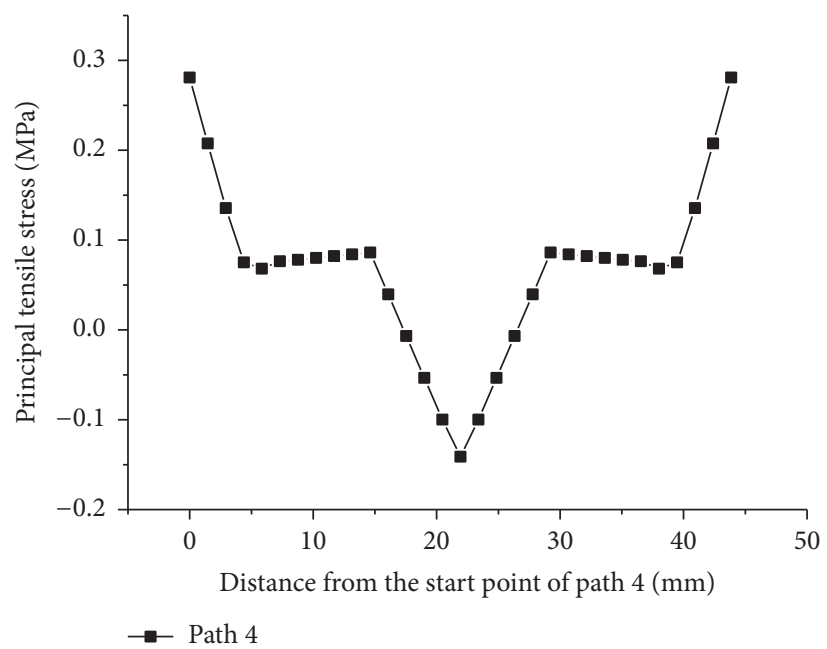

FIgURE 36: Principal tensile stress in the concrete specimen prestressed under a load of $10 \mathrm{MPa}$ when the displacement resulting from corrosion-induced expansion reaches $0.031 \mathrm{~mm}$. 


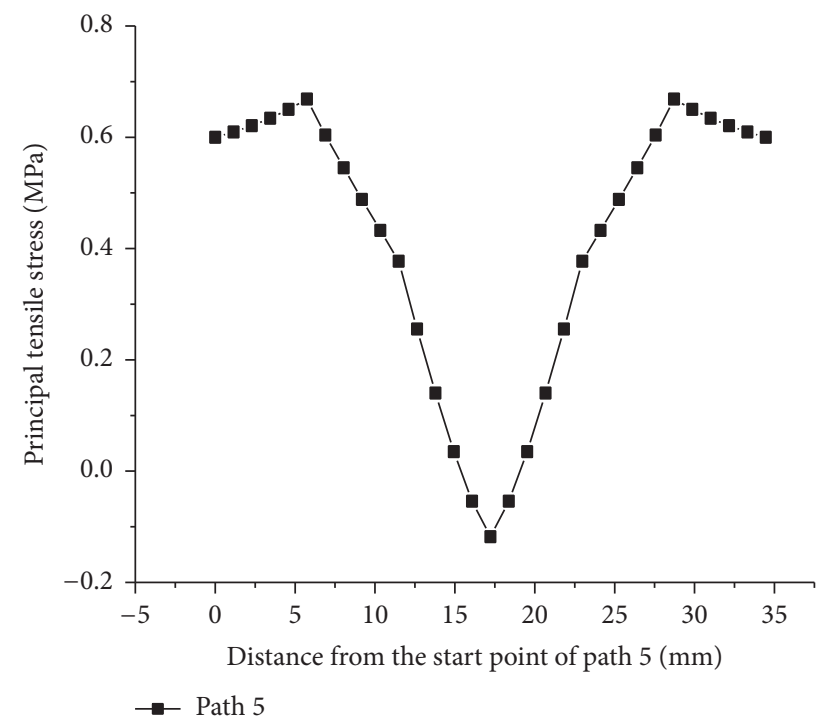

FIgURE 37: Principal tensile stress in the concrete specimen prestressed under a load of $10 \mathrm{MPa}$ when the displacement resulting from corrosion-induced expansion reaches $0.031 \mathrm{~mm}$.

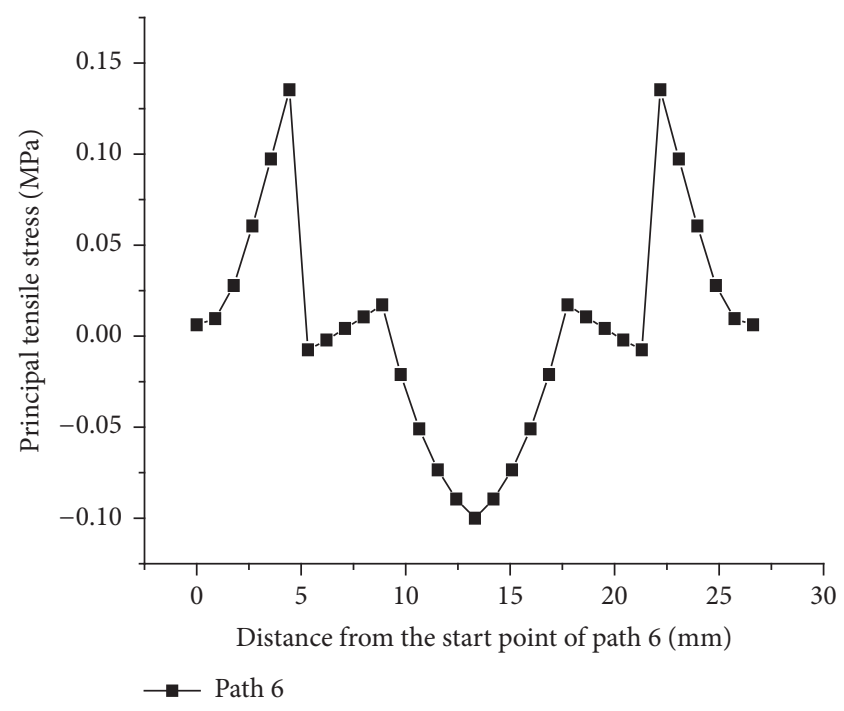

FIGURE 38: Principal tensile stress in the concrete specimen prestressed under a load of $10 \mathrm{MPa}$ when the displacement resulting from corrosion-induced expansion reaches $0.031 \mathrm{~mm}$.

formed inside the protective layer as a result of corrosioninduced expansion using spatial FEM software. These nephograms clearly show the change in the stress field in the surrounding concrete caused by the rebar displacement resulting from corrosion-induced expansion, that is, the effect of rebar corrosion on the stress field in local concrete during its service life.

(3) By simulating the prestress condition of concrete, the effect of rebar corrosion on the surrounding stress field is analyzed. It is found that prestressing concrete under a compressive load can retard crack formation resulting from rebar corrosion-induced concrete expansion.

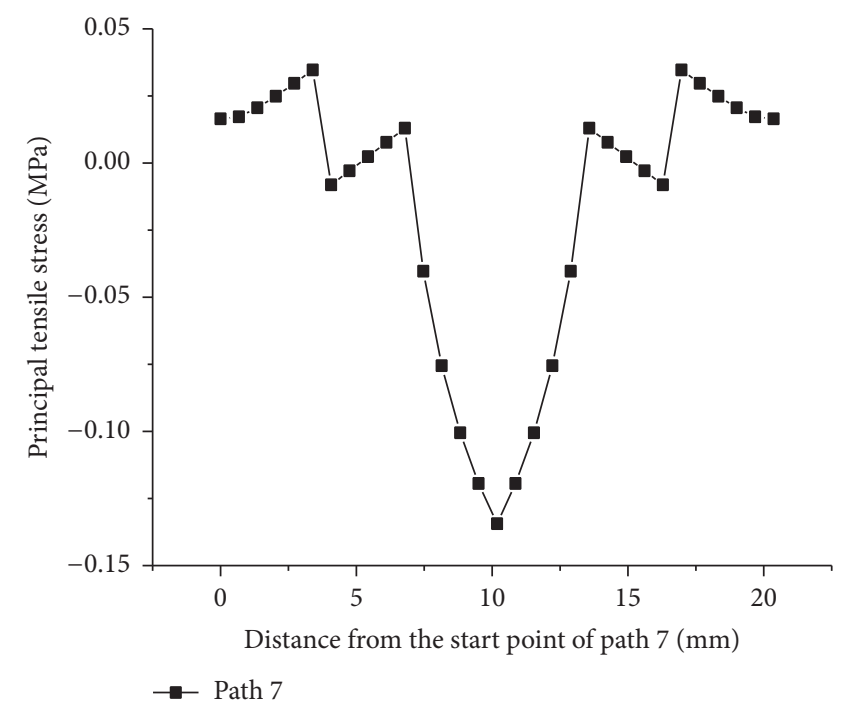

FIGURE 39: Principal tensile stress in the concrete specimen prestressed under a load of $10 \mathrm{MPa}$ when the displacement resulting from corrosion-induced expansion reaches $0.031 \mathrm{~mm}$.

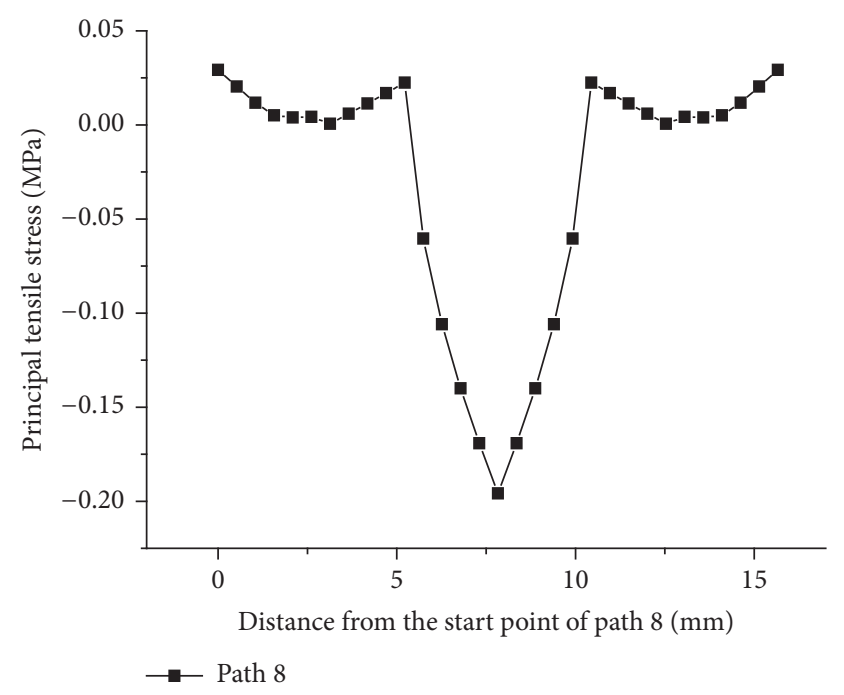

FIgURE 40: Principal tensile stress in the concrete specimen prestressed under a load of $10 \mathrm{MPa}$ when the displacement resulting from corrosion-induced expansion reaches $0.031 \mathrm{~mm}$.

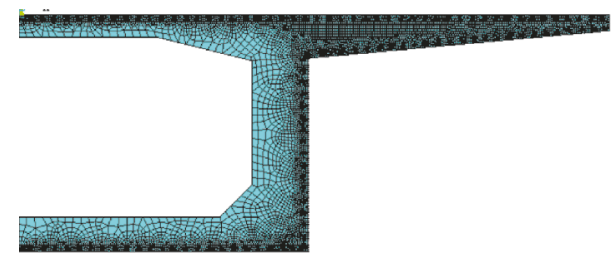

FIGURE 41: Element mesh generation for the transverse cross-section of half of an actual bridge. 

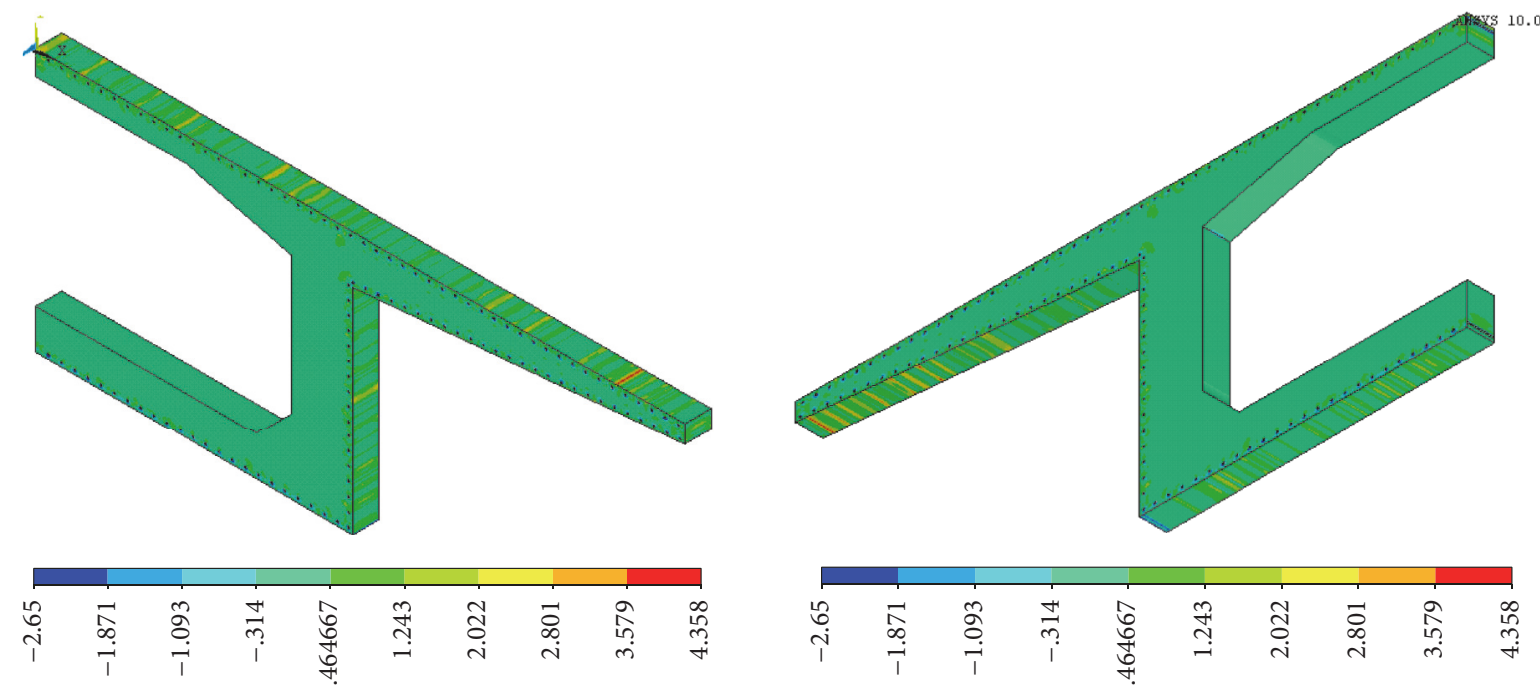

FIGURE 42: Principal tensile stress from two perspectives.

(4) The simulation analysis of an actual corroded bridge shows that once the amount of the product of rebar corrosion reaches a certain level, it will result in the generation of a relatively high tensile stress in the surrounding concrete as well as a change in the local stress field in the concrete and crack formation within a double-protective layer thickness range.

\section{Conflicts of Interest}

The authors declare that there are no conflicts of interest regarding the publication of this paper.

\section{Acknowledgments}

This research was supported by the National Basic Research Program of China (973 Program) under Grant no. 2013 CB036303.

\section{References}

[1] K. R. Gowers and S. G. Millard, "Measurement of concrete resistivity for assessment of corrosion severity of steel using wenner technique," ACI Materials Journal, vol. 96, no. 5, pp. 536-541, 1999.

[2] B. Richard, M. Quiertant, V. Bouteiller et al., "Experimental and numerical analysis of corrosion-induced cover cracking in reinforced concrete sample," Computers and Concrete, vol. 18, no. 3, pp. 421-439, 2016.

[3] Rasheeduzzafar, S. S. Al-Saadoun, and A. S. Al-Gahtani, "Corrosion cracking in relation to bar diameter, cover, and concrete quality," Journal of Materials in Civil Engineering, vol. 4, no. 4, pp. 327-342, 1992.

[4] A. Xu and A. Shayan, "Relationship between reinforcing bar corrosion and concrete cracking," ACI Materials Journal, vol. 113, no. 1, pp. 3-12, 2016.

[5] M. Raupach, "Chloride-induced macrocell corrosion of steel in concrete-Theoretical background and practical consequences,"
Construction and Building Materials, vol. 10, no. 5, pp. 329-338, 1996.

[6] M. J. Mirzaee, F. J. Alaee, M. Hajsadeghi, and C. S. Chin, "Numerical simulation of the through-thickness cracking of concrete cover due to steel reinforcing bars corrosion," 2016.

[7] M. Hastak, A. Mirmiran, and D. Richard, "A framework for lifecycle cost assessment of composites in construction," Journal of Reinforced Plastics and Composites, vol. 22, no. 15, pp. 1409-1429, 2003.

[8] S. C. Paul and G. P. A. G. van Zijl, "Chloride-induced corrosion modelling of cracked reinforced SHCC," Archives of Civil and Mechanical Engineering, vol. 16, no. 4, pp. 734-742, 2016.

[9] M. P. Enright and D. M. Frangopol, "Probabilistic analysis of resistance degradation of reinforced concrete bridge beams under corrosion," Engineering Structures, vol. 20, no. 11, pp. 960$971,1998$.

[10] Y. Zhao, J. Dong, Y. Wu, and W. Jin, "Corrosion-induced concrete cracking model considering corrosion product-filled paste at the concrete/steel interface," Construction and Building Materials, vol. 116, pp. 273-280, 2016.

[11] D.-J. Yoon, W. J. Weiss, and S. P. Shah, "Assessing damage in corroded reinforced concrete using acoustic emission," Journal of Engineering Mechanics, vol. 126, no. 3, pp. 273-283, 2000.

[12] S. J. Williamson and L. A. Clark, "Pressure required to cause cover cracking of concrete due to reinforcement corrosion," Magazine of Concrete Research, vol. 52, no. 6, pp. 455-467, 2000.

[13] Y. Liu and R. E. Weyers, "Modeling the time-to-corrosion cracking in chloride contaminated reinforced concrete structures," ACI Materials Journal, vol. 95, no. 6, pp. 675-681, 1998.

[14] F. Li and Y. Shen, "Full-scale test of the hydration heat and the curing method of the wet joints of a precast segmental pier of a bridge," European Journal of Environmental and Civil Engineering, pp. 1-23, 2015.

[15] Q.-P. Wang, "Experimental study and theoretic analysis on damage rule of corroded and cracked reinforced concrete," Hohai University, vol. 5, 2004.

[16] X.-P. Yang, R.-G. Liu, and Z.-T. Lv, "Experimental study on the influence of crack on durability of prestressed concrete structure," Journal of Jiangsu University (Natural Science), vol. 23, no. 11, pp. 90-94, 2002. 
[17] Y.-J. Mou, Y.-S. Yuan, and Y.-S. Ji, "Concrete stress analysis based on steel corrosion expansion," Journal of Huaihai Institute of Technology (Natural Sciences Edition), vol. 21, no. 1, pp. 66-70, 2006.

[18] E. Gebreyouhannes and K. Maekawa, "Nonlinear gel migration in cracked concrete and broken symmetry of corrosion profiles," Journal of Advanced Concrete Technology, vol. 14, no. 6, pp. 271286, 2016

[19] Z. Jin, X. Zhao, T. Zhao, and L. Yang, "Corrosion and 3D crackpropagation behaviors in reinforced concrete subjected to bending load in simulated marine environment," International Journal of Electrochemical Science, vol. 11, no. 10, pp. 8779-8796, 2016.

[20] N. Xia, Q.-W. Ren, and Z.-L. Li, "Numerical simulation and analysis of cover splitting due to corrosion in anchorage zone of bolts," Chinese Journal of Rock Mechanics and Engineering, vol. 25, no. 7, pp. 1481-1485, 2006. 

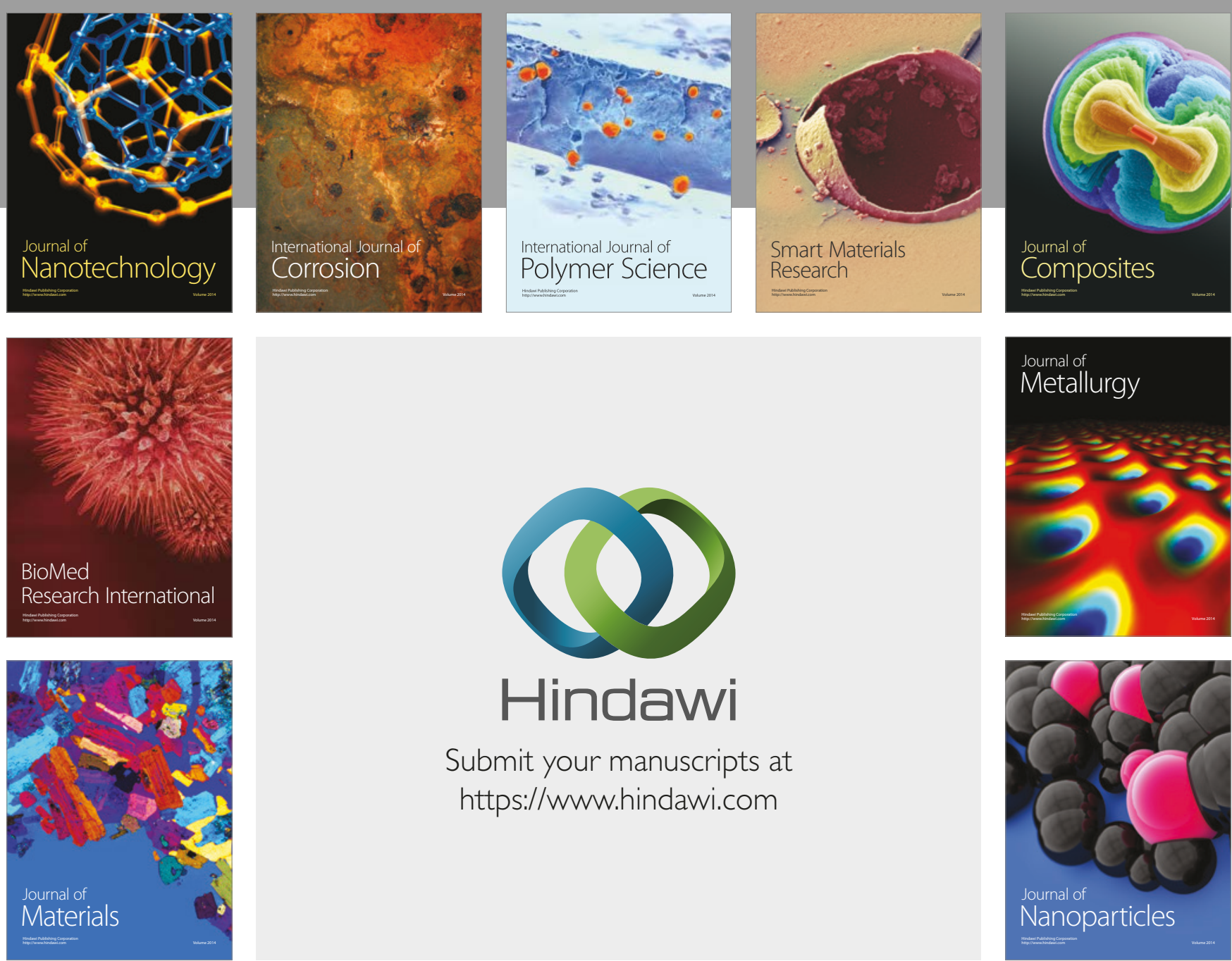

\section{Hindawi}

Submit your manuscripts at

https://www.hindawi.com
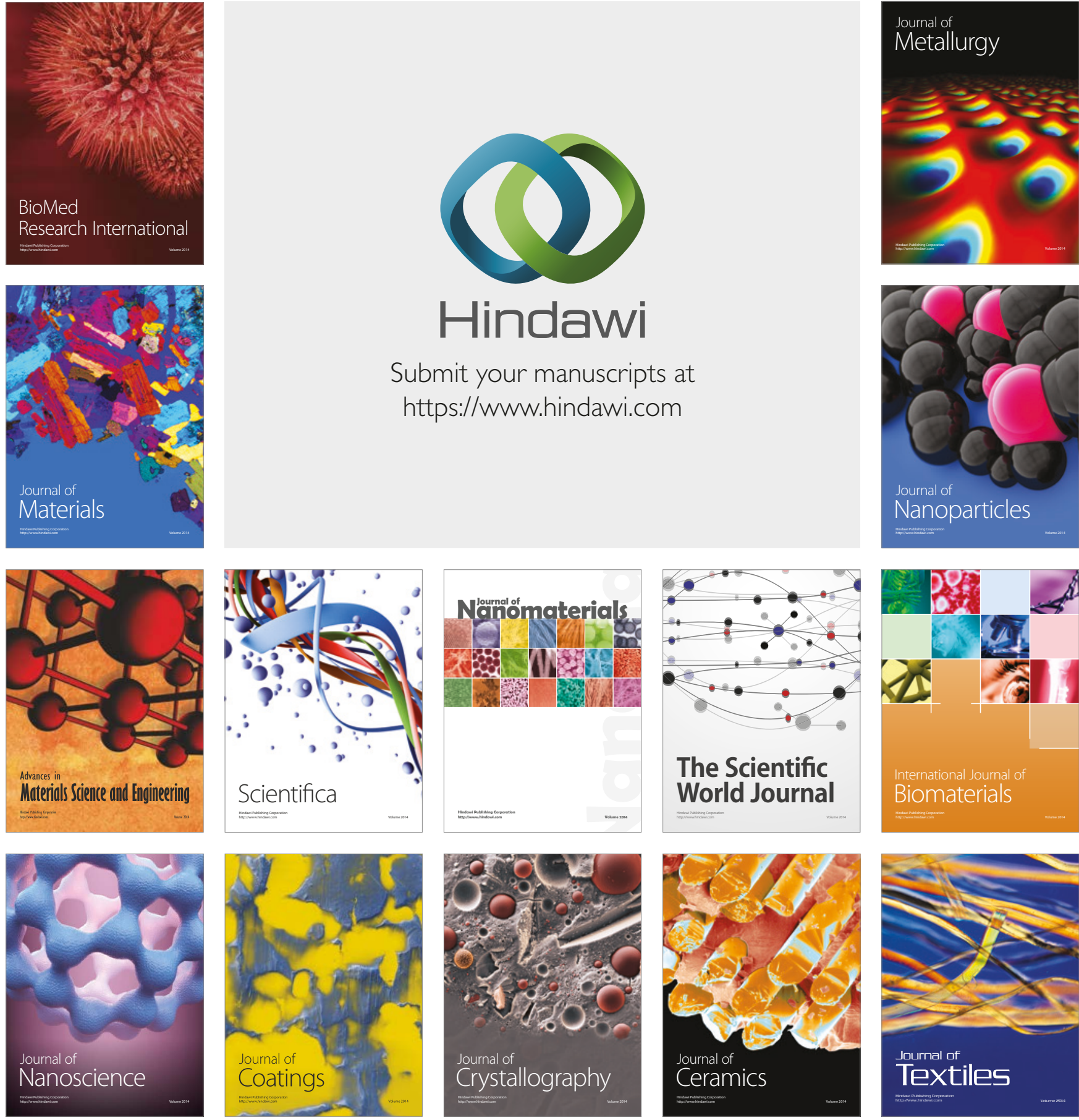

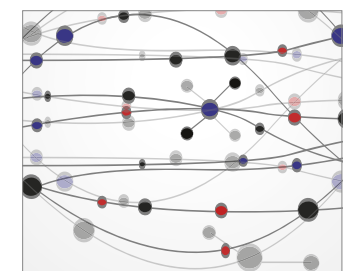

The Scientific World Journal
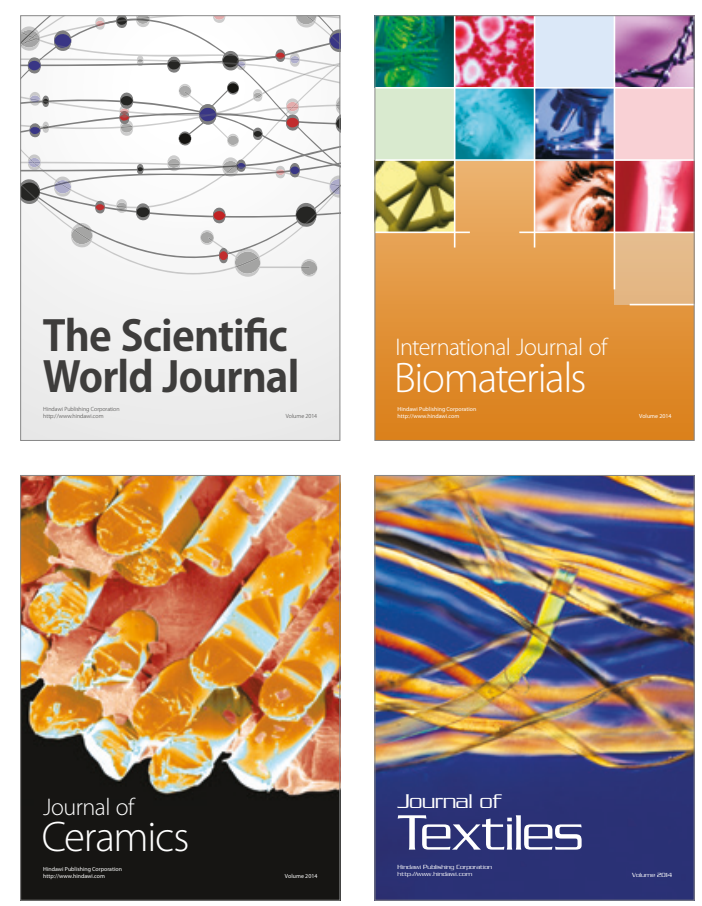